\title{
Herbal Products in Postsurgical Wound Healing - Incision, Excision and Dead Space Wound Models
}

\author{
Authors \\ Anna Herman ${ }^{1}$, Andrzej P. Herman ${ }^{2}$ \\ Affiliations \\ 1 Faculty of Health Sciences, Warsaw School of Engineering \\ and Health, Warsaw, Poland \\ 2 Department of Genetic Engineering, The Kielanowski \\ Institute of Animal Physiology and Nutrition, Polish \\ Academy of Sciences, Jabłonna near Warsaw, Poland
}

\section{Key words}

herbal products, wound healing, incision wound model, excision wound model, dead space wound model

\author{
received February 20, 2020 \\ revised April 19, 2020 \\ accepted April 20, 2020
}

\author{
Bibliography \\ DOI https://doi.org/10.1055/a-1162-9988
}

published online May 18, 2020 | Planta Med 2020; 86: 732748 @ Georg Thieme Verlag KG Stuttgart · New York |

ISSN 0032-0943

\section{Correspondence}

Anna Herman, PhD, DSc, Prof.

Warsaw School of Engineering and Health,

Faculty of Health Sciences

Bitwy Warszawskiej 192018 street, 02-366 Warsaw, Poland

Phone: + 48228567044 , Fax: + 48226463418

anna.herman@onet.pl

\section{ABSTRACT}

The purpose of this review is to summarize current knowledge acquired on preclinical (incision, excision, and dead space wound models) and clinical studies regarding topically used herbal products with wound healing activity. The antimicrobial, anti-inflammatory, and antioxidant mechanisms of their action as well as the adverse effects of herbal therapy will be described. Numerous preclinical and few clinical trials have confirmed the activity of herbal products in the stimulation of wound healing. In contrast to synthetic drugs, for which chemical compositions, purity, efficacy, minimal active concentration, and toxicity are well specified, several herbal formulations require further investigations. Nevertheless, it cannot be precluded that herbal products may be considered as an important support during conventional wound healing therapy or even as synthetic medicament replacements.

\section{Introduction}

Wound healing is a complex, multifactorial sequence of events involving cellular and biochemical processes initiated in response to an injury that restores the function and integrity of damaged tissues [1]. Wound healing involves continuous cell-cell and cell-matrix interactions occurring in 4 overlapping phases: (1) coagulation controlling excessive blood loss from the damaged vessels; (2) inflammation (0-3 days); (3) re-epithelialization including the proliferation, migration, and differentiation of epithelial cells of the epidermis (3-12 days); and (4) collagen deposition and remodeling within the dermis (3-6 mo.) [2]. In wound healing, the activity of an intricate network of blood cells, cytokines [tumor necrosis factor alpha (TNF $\alpha$ ), and interleukin (IL) family], growth factors [transforming growth factor beta (TGF $\beta)$, platelet-derived growth factors, epidermal growth factor, insulin-like growth fac- tor (IGF-1), fibroblast growth factor, vascular endothelial growth factor (VEGF), granulocyte macrophage colony stimulating factor (GM-CSF), and connective tissue growth factor (CTGF)], extracellular matrix (ECM) proteins (integrin, matrikines, laminin, and fibronectin), and matrix metalloproteinases (MMPs) is involved, ultimately leading to the tissue repair and regeneration [3-5].

Wound healing therapies can be broadly classified into 2 categories: traditional (herbal- and animal-derived compounds, living organisms, silver-based products, and traditional dressings) and modern (grafts, modern dressings, bioengineered skin substitutes, and cell/growth factor therapies). These therapies have distinct levels of efficacy, clinical acceptance, and side effects [6]. Herbal drugs are the most commonly used traditional therapies for the treatment of skin wounds owing to their effectiveness and safety [7]. Data on the antibacterial and wound healing activities, such as coagulation, inflammation, fibroplasia, epithe- 
lialization, collagenation, and wound contraction, of herbs are abundant in the scientific literature [8,9]. Moreover, a highly reduced wound healing time is associated with a low chance of infection, complications, and cost. Owing to the variety of biologically active compounds produced by plants, it appears that herbal products can be successfully used as stimulators for the wound healing process.

In the present review, the current knowledge on topically used herbal products for wound healing was summarized based on the search of several electronic databases concerning preclinical (incision, excision, and dead space wound models) and clinical studies. The antimicrobial, anti-inflammatory, and antioxidant mechanisms of their action as well as the adverse effects of herbal therapy will be described.

\section{Literature Search Strategy}

The PubMed, Scopus, and Google Scholar databases were searched for articles published from 2015 to the present. Search terms included "herbs and skin wounds", "topical herbal treatments for wound healing", "herbal treatments in incision wound model", "herbal treatments in excision wound model", and "herbal treatments in dead space wound model".

\section{Inclusion and exclusion criteria}

For this review, studies pertaining to the topical administration of herbal products in wound healing (animal and human studies) were included, whereas those pertaining to the oral and systemic administration of herbal products were excluded. Only publications concerning topical application of herbal products to wounds after surgeries performed according to the incision, excision, and dead space wound model were included. A burn wound healing model was excluded from the study. Moreover, publications in languages other than English were excluded.

\section{Study selection}

Overall, 84117 articles were found via the search of the databases. From these 61742 articles at the titles level, duplicates and unrelated articles were removed, leaving 7410 articles for eligibility check. Finally, 86 articles were used for the review ( $\vee$ Fig. 1).

\section{Herbs Used for Treatment of Wounds}

Herbal products have been used in skin wound care for centuries because of their therapeutic effects, including anti-inflammatory, antioxidant, and antimicrobial activities [8,9]. The clinical efficacy of herbal products has been investigated via in vivo trials using both animal and human models. The most commonly used models for postsurgical wound healing are incision, excision, and dead space wound models ( $\bullet$ Fig. 2 ).

\section{Animal-based Studies}

Animals, particularly rats and mice, are important models in the research on the effects of herbal products on wound healing. These models attempt to reflect human wound healing issues,

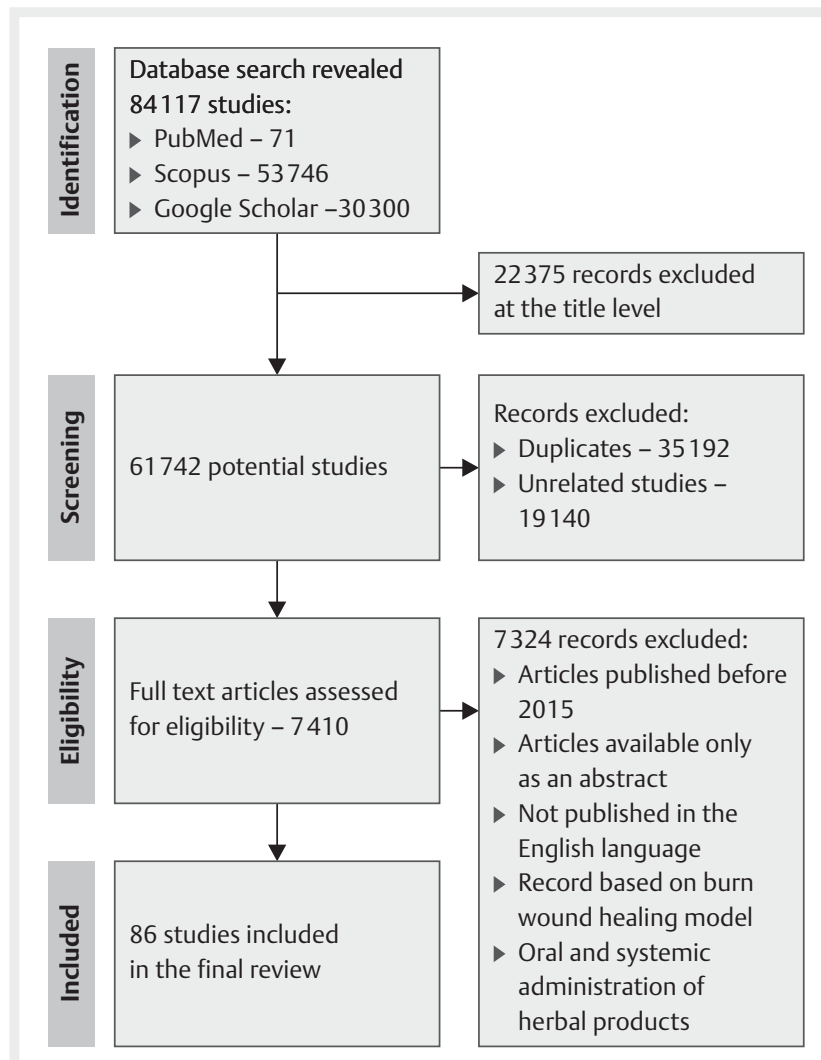

- Fig. 1 Search strategy used to identify relevant articles.

and it is thus easier to achieve approximations to the clinical situation [10]. However, it should be taken into account that many aspects of the anatomy of the skin (pigmentation, dermis, adipose tissue, skin appendages) are unique to humans compared to mice/rats. The epidermis of mice and rats have similar organization but is much thinner than the human epidermis, and their dermal connective tissue do not contain elastic fibers [2]. Moreover, the human hair follicle density is much lower than that of small animals with an abundant fur [2]. Therefore, partial-thickness wounds are rarely studied in small furred animals, because (1) performation partial-thickness wounds is a challenge; and (2) the extremely high hair density in small furred animals exaggeratedly intensifies the rate of re-epithelialization [2]. Therefore, hairless species, among them humans and pigs, are generally preferred.

\section{Incision wound model}

In rats, incisional wounds were made by sharp blade or scalpel cuts on the depilated skin of their back with no tissue loss and minimal tissue damage. The incisional wound model has been suggested to be a particularly reproducible model for scarring research and a clinically useful model for the determination of wound tensile strength [10]. Herbal products with wound healing potential tested in incision wound model are reported in $>$ Table 1. All herbal products improved wound healing activity via significant wound closure, increased wound breaking strength, and tensile strength, and resulted in faster wound healing in treated 


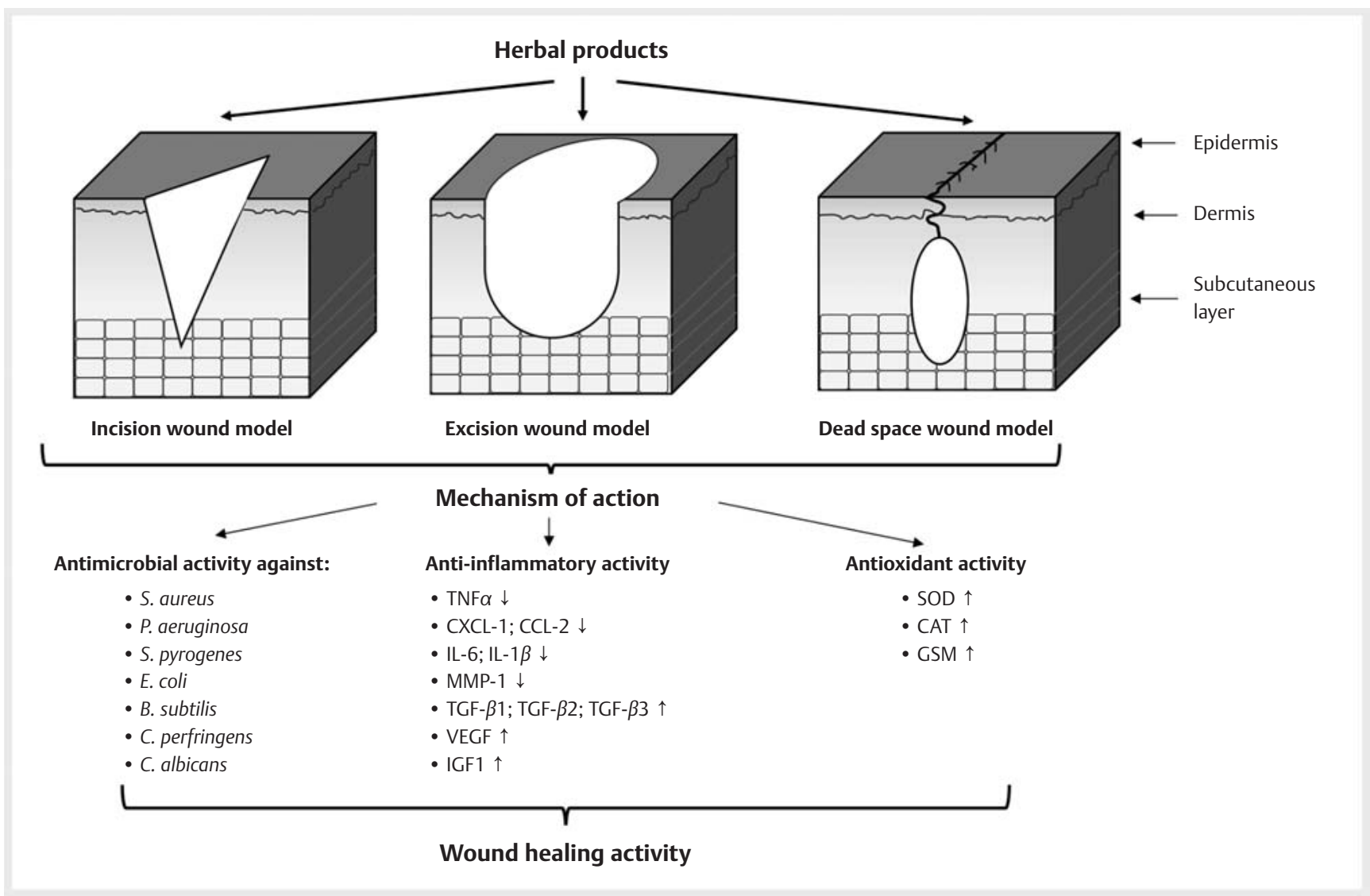

Fig. 2 Herbal products in postsurgical wound healing activity: mechanisms of action.

group compared with the control (untreated) group and active therapy (povidone-iodine, silver sulfadiazine, neomycin sulfate, gentamicin, and bacitracin zinc) group.

\section{Excision wound model}

In rats, excisional wounds were induced by the removal of some part of the skin (typically the dorsal thoracic region) at the depth of the epidermis and upper dermis-a partial thickness (or splitthickness) wound-or both epidermis and dermis up to the fascia or subcutaneous tissue-a full-thickness wound. The wounds can be left open or covered with a dressing. Excisional wounds are suggested to aid the assessment of wound re-epithelialization and wound contraction [10]. Herbal products with wound healing potential studied on excision wound models are presented in - Table 2. All herbal products showed rapid wound contraction in shorter time, increased wound breaking strength, increased epithelialization, and granulation that is better or comparable to that of standard drugs (povidone-iodine, silver sulfadiazine, solcoseryl gel, tetracycline, neomycin sulfate, gentamycin, and amoxicillin).

\section{Dead space wound model}

The subcutaneous dead space wounds were created in the region of axilla and groin by making a pouch via a small nick in the skin. This dead space is an open area in closed tissue that prevents a tissue apposition and provides a space for blood and other fluid influx as well as for microbial infection. Such model is suggested for the assessment of changes in the granuloma tissue as well as for the biochemical analysis of metabolites, cytokines, and growth factors [10]. To examine the action of herbal products in wound repair, test agents can be injected or implanted into the chamber as well as orally administered. Unfortunately, most dead space wound model studies described in the present review are based on the oral administration of herbal products $[13,19,23$, $29,77]$. Only a few studies have described the topical application of herbal products ( $\bullet$ Table 3 ).

\section{Human-based Studies}

In comparison to several animal-based studies, there are only a few clinical trials describing the influence of herbal products and polyherbal formulation on wound healing ( $\bullet$ Table 4 ). This imbalance arises from the fact that herbal products should be prepared according to some international standards in regard to the quality, purity, and sterility. Moreover, clinical trials designed to prove the efficacy of herbs as active compounds of wound healing formulations and to demonstrate their safety are expensive, prolonged, and require special permission from the regulatory authorities. Despite these limitations, some scientific studies are being performed. 
- Table 1 Herbs used for treatment of incision wounds, animal-based studies.

\begin{tabular}{|c|c|c|c|c|c|c|}
\hline Herbs & Animals & Pharmacological data & Effect & $\begin{array}{l}\text { Mechanism } \\
\text { of action }\end{array}$ & $\begin{array}{l}\text { Anti- } \\
\text { microbial } \\
\text { activity }\end{array}$ & Ref \\
\hline $\begin{array}{l}\text { Acalypha indica } \\
\text { extract }\end{array}$ & Mice & $\begin{array}{l}5 \%, 10 \% \text {, and } 20 \% \text { ethanol leaf extract } \\
\text { of } A . i n d i c a \text { in ointment; } \\
\text { control: ointment base; } \\
\text { positive control: } 10 \% \text { povidone iodine } \\
\text { ointment; } \\
\text { treatment: twice a day for } 14 \text { days }\end{array}$ & $\begin{array}{l}5 \% \text { and } 10 \% \text { extracts ointment } \\
\text { showed better changes in the } \\
\text { wound size comparison to placebo } \\
\text { and standard groups; } \\
\text { only } 10 \% \text { of extract ointment pro- } \\
\text { motes the formation of granulation } \\
\text { tissue, allowing the reepithelization } \\
\text { phase }\end{array}$ & - & - & [11] \\
\hline $\begin{array}{l}\text { Achillea asiatica } \\
\text { extract }\end{array}$ & $\begin{array}{l}\text { Sprague- } \\
\text { Dawley } \\
\text { rats }\end{array}$ & $\begin{array}{l}3 \% \text { A. asiatica extract; } \\
\text { control: saline (vehicle); } \\
\text { positive control: } 3 \% \text { Centella asiatica } \\
\text { extract; } \\
\text { treatment: once a day for } 14 \text { days }\end{array}$ & $\begin{array}{l}\text { significantly increased epithe- } \\
\text { lialization and accelerated wound } \\
\text { healing }\end{array}$ & $\begin{array}{l}\text { anti- } \\
\text { inflamma- } \\
\text { tory activity }\end{array}$ & - & {$[12]$} \\
\hline $\begin{array}{l}\text { Achyranthes } \\
\text { aspera extract }\end{array}$ & $\begin{array}{l}\text { Wistar } \\
\text { rats }\end{array}$ & $\begin{array}{l}10 \%(\mathrm{w} / \mathrm{w}) \text { ethanolic extracts in } \\
\text { ointment; } \\
\text { control: ointment base; } \\
\text { positive control: } 5 \% \text { povidone iodine } \\
\text { ointment; } \\
\text { treatment: once a day for } 10 \text { days }\end{array}$ & $\begin{array}{l}\text { wound breaking strength was sig- } \\
\text { nificantly increased in extract treat- } \\
\text { ed group in comparison to control }\end{array}$ & - & - & [13] \\
\hline $\begin{array}{l}\text { Aegle marmelos, } \\
\text { Mucuna pruriens } \\
\text { extract }\end{array}$ & $\begin{array}{l}\text { Wistar } \\
\text { rats }\end{array}$ & $\begin{array}{l}\text { hydrogel with } 2.5 \% \text { ethyl acetate/ } \\
\text { methanolic/aqueous } A \text {. marmelos } \\
\text { or } M \text {. pruriens extracts; } \\
\text { control: untreated group; } \\
\text { positive control: Hydroheal; } \\
\text { treatment: once daily for } 12 \text { days }\end{array}$ & $\begin{array}{l}\text { both hydrogels with methanolic } \\
\text { extracts showed significant increase } \\
\text { in tensile strength }\end{array}$ & - & - & [14] \\
\hline $\begin{array}{l}\text { Agave americana } \\
\text { extract }\end{array}$ & $\begin{array}{l}\text { Wistar } \\
\text { rats }\end{array}$ & $\begin{array}{l}5 \% \text { and } 10 \% \text { ointment with hydro- } \\
\text { alcoholic } A \text {. americana leaf extract; } \\
\text { control: ointment base; } \\
\text { positive control: Soframycin ointment; } \\
\text { treatment: once daily for } 16 \text { days }\end{array}$ & $\begin{array}{l}\text { improved wound healing activity } \\
\text { and increased tensile strength; } \\
\text { rate of epithelialization almost } \\
\text { comparable to Soframycin }\end{array}$ & - & - & [15] \\
\hline Aloe vera gel & Rabbits & $\begin{array}{l}\text { A. vera gel in Acacia honey; } \\
\text { positive control: pyodine; } \\
\text { treatment: twice daily for } 10 \text { days }\end{array}$ & $\begin{array}{l}\text { wound contraction was higher in } \\
\text { treated group than in control group } \\
\text { and increased at day } 10\end{array}$ & - & - & [16] \\
\hline $\begin{array}{l}\text { Alpinia galanga } \\
\text { extract }\end{array}$ & $\begin{array}{l}\text { Wistar } \\
\text { rats }\end{array}$ & $\begin{array}{l}2 \% \text { and } 5 \%(\mathrm{w} / \mathrm{w}) \text { petroleum ether } \\
\text { and ethanolic extract in ointment; } \\
\text { positive control: povidone iodine } \\
\text { ointment; } \\
\text { treatment: once a day for } 9 \text { days }\end{array}$ & $\begin{array}{l}\text { ethanol extract showed significantly } \\
\text { faster wound healing; } \\
\text { significant increase in the tensile } \\
\text { strength }\end{array}$ & $\begin{array}{l}\text { antioxidant } \\
\text { activity }\end{array}$ & - & [17] \\
\hline $\begin{array}{l}\text { Andrographis } \\
\text { paniculata extract }\end{array}$ & $\begin{array}{l}\text { Wistar } \\
\text { rats }\end{array}$ & $\begin{array}{l}\text { A. paniculata methanolic extracts } \\
(100 \mathrm{mg} / \mathrm{kg} / 200 \mathrm{mg} / \mathrm{kg} / 400 \mathrm{mg} / \mathrm{kg}) \text {; } \\
\text { control: untreated group; } \\
\text { positive control: } 1 \% \text { Framycetin } \\
\text { sulphate cream; } \\
\text { treatment: once a day for } 10 \text { days }\end{array}$ & $\begin{array}{l}\text { extracts were found to have } \\
\text { greater wound healing activity and } \\
\text { increased breaking strength }\end{array}$ & $\begin{array}{l}\text { antifungal } \\
\text { activity }\end{array}$ & C. albicans & [18] \\
\hline $\begin{array}{l}\text { Archidium } \\
\text { ohioense } \\
\text { essential oil }\end{array}$ & $\begin{array}{l}\text { Wistar } \\
\text { rats }\end{array}$ & $\begin{array}{l}\text { A. ohioense oil ( } 0.5 \text { and } 1.0 \mathrm{mg} / \mathrm{kg} \\
\text { bwt); } \\
\text { control: untreated group; } \\
\text { positive control: gentamicin; } \\
\text { treatment: once daily for } 10 \text { days }\end{array}$ & $\begin{array}{l}\text { enhanced wound breaking strength } \\
\text { and contraction rate, tissue collagen } \\
\text { formation, and early epithelization } \\
\text { period }\end{array}$ & - & - & [19] \\
\hline $\begin{array}{l}\text { Atropa belladonna } \\
\text { extract }\end{array}$ & $\begin{array}{l}\text { Sprague- } \\
\text { Dawley } \\
\text { rats }\end{array}$ & $\begin{array}{l}\text { extract in water tincture }(8 \mathrm{~g} / 1 \mathrm{~L}) \\
\text { control: untreated group; } \\
\text { treatment: once a day, } 2 \text { and } 5 \text { days } \\
\text { after surgery }\end{array}$ & $\begin{array}{l}\text { tensile strength of tincture was } \\
\text { significantly higher than in the } \\
\text { untreated group }\end{array}$ & - & - & cont. \\
\hline
\end{tabular}


- Table 1 Continued

\begin{tabular}{|c|c|c|c|c|c|c|}
\hline Herbs & Animals & Pharmacological data & Effect & $\begin{array}{l}\text { Mechanism } \\
\text { of action }\end{array}$ & $\begin{array}{l}\text { Anti- } \\
\text { microbial } \\
\text { activity }\end{array}$ & Ref \\
\hline $\begin{array}{l}\text { Coleus blumei } \\
\text { extract }\end{array}$ & $\begin{array}{l}\text { Wistar } \\
\text { rats }\end{array}$ & $\begin{array}{l}\text { C. blumei (mayana) leaves ointment; } \\
\text { control: untreated group; } \\
\text { treatment: } 15 \mathrm{mg} \text {, once a day for } \\
13 \text { days }\end{array}$ & $\begin{array}{l}\text { higher wound contraction in } \\
\text { comparison to the control group }\end{array}$ & - & - & {$[21]$} \\
\hline $\begin{array}{l}\text { Curcuma longa, } \\
\text { Cynodon dactylon } \\
\text { extract }\end{array}$ & $\begin{array}{l}\text { Cattle } \\
\text { (Bos } \\
\text { indicus) }\end{array}$ & $\begin{array}{l}\text { fresh C. longa and C. dactylon pastes; } \\
\text { control: solution ( } 10 \% \text { benzoin, } 90 \% \\
\text { alcohol with aloes, storax, and Tolu } \\
\text { balsam); } \\
\text { treatment: daily for } 21 \text { days }\end{array}$ & $\begin{array}{l}\text { C. dactylon paste exerted wound } \\
\text { healing activity but less effective } \\
\text { than that of } C \text {. longa }\end{array}$ & - & - & {$[22]$} \\
\hline $\begin{array}{l}\text { Curcuma longa, } \\
\text { Eclipta alba, Tridax } \\
\text { procumbens } \\
\text { extract }\end{array}$ & $\begin{array}{l}\text { Wistar } \\
\text { rats }\end{array}$ & $\begin{array}{l}\text { poly herbal formulation with } 5 \% \text { and } \\
10 \% \text {; } \\
\text { control: gel base; } \\
\text { positive control: Aloe vera ( } 90 \%) \text { gel; } \\
\text { treatment: once a day for } 10 \text { days }\end{array}$ & $\begin{array}{l}\text { breaking strength of wound was } \\
\text { significantly increased in all treat- } \\
\text { ment groups when compared to } \\
\text { control group }\end{array}$ & - & - & [23] \\
\hline $\begin{array}{l}\text { henna, } \\
\text { pomegranate and } \\
\text { myrrh extracts }\end{array}$ & $\begin{array}{l}\text { Wistar } \\
\text { rats }\end{array}$ & $\begin{array}{l}\text { methanolic extracts alone or in a com- } \\
\text { bination as a total concentration of } \\
\text { 15\% w/w in hydrophilic ointments; } \\
\text { negative control: base ointment alone; } \\
\text { positive control: gentamycin oint- } \\
\text { ment; } \\
\text { treatment: twice daily for } 24 \text { days }\end{array}$ & $\begin{array}{l}\text { blended formulation showed the } \\
\text { highest increase in the percent of } \\
\text { wound contraction and decrease in } \\
\text { the epithelization period; compara- } \\
\text { ble results to the standard ointment }\end{array}$ & $\begin{array}{l}\text { anti- } \\
\text { microbial } \\
\text { activity }\end{array}$ & $\begin{array}{l}\text { C. albi- } \\
\text { cans, } \\
\text { S. aureus, } \\
\text { E. coli }\end{array}$ & {$[24]$} \\
\hline $\begin{array}{l}\text { Hydrolea zeylanica } \\
\text { extract }\end{array}$ & $\begin{array}{l}\text { Wistar } \\
\text { rats }\end{array}$ & $\begin{array}{l}5 \%(w / w) \text { aqueous and methanol } \\
\text { extract in ointment; } \\
\text { negative control: ointment base; } \\
\text { positive control: povidone iodine } 5 \% \\
(\mathrm{w} / \mathrm{w}) \text {; treatment: } 10 \text { days }\end{array}$ & $\begin{array}{l}\text { increased rate of wound contrac- } \\
\text { tion, decreased period of epitheliza- } \\
\text { tion and increased skin breaking } \\
\text { strength }\end{array}$ & - & - & {$[25]$} \\
\hline $\begin{array}{l}\text { Jatropha curcas } \\
\text { latex }\end{array}$ & Mice & $\begin{array}{l}10 \% \text { and } 15 \% \text { J. curcas latex in cream; } \\
\text { control: base cream; } \\
\text { positive control: sulfadiazine } 0.1 \% \\
\text { cream; } \\
\text { treatment: twice a day for } 10 \text { days }\end{array}$ & $\begin{array}{l}\text { both creams revealed moderate } \\
\text { immune reaction to CD34 and } \\
\text { angiogenesis activity }\end{array}$ & $\begin{array}{l}\text { anti- } \\
\text { inflamma- } \\
\text { tory activity; } \\
\text { angiogene- } \\
\text { sis activity }\end{array}$ & - & {$[26]$} \\
\hline $\begin{array}{l}\text { Macroptilium } \\
\text { atropurpureum } \\
\text { extract }\end{array}$ & $\begin{array}{l}\text { Wistar } \\
\text { rats }\end{array}$ & $\begin{array}{l}\text { ointment with } 10 \%(\mathrm{w} / \mathrm{w}) \text { petroleum } \\
\text { ether and } 10 \%(\mathrm{w} / \mathrm{w}) \text { aqueous } \\
\text { extracts; } \\
\text { control: untreated group; } \\
\text { positive control: } 15 \% \text { Silver sulfadia- } \\
\text { zine; } \\
\text { treatment: until complete healing }\end{array}$ & $\begin{array}{l}\text { increased wound healing activity } \\
\text { compared to standard drug }\end{array}$ & - & - & {$[27]$} \\
\hline $\begin{array}{l}\text { Momordica } \\
\text { charantia, } \\
\text { Pongamia glabra, } \\
\text { Piper nigrum } \\
\text { extracts }\end{array}$ & $\begin{array}{l}\text { Wistar } \\
\text { rats }\end{array}$ & $\begin{array}{l}10 \% \text { and } 15 \% \text { alcoholic and aqueous } \\
\text { extracts of } M \text {. charantia } 1: 1 \text { in oint- } \\
\text { ment, } 10 \% \text { and } 15 \% \text { alcoholic and } \\
\text { aqueous extracts of } P \text {. glabra } 1: 1 \text { in } \\
\text { ointment, } 10 \% \text { and } 15 \% \text { alcoholic and } \\
\text { aqueous extracts of } P \text {. nigrum } 1: 1 \text { in } \\
\text { ointment; } \\
\text { control: ointment base; } \\
\text { positive control: Povidone iodine } \\
\text { ointment; } \\
\text { treatment: once daily for } 10 \text { days }\end{array}$ & $\begin{array}{l}\text { decreased wound area, no mortality } \\
\text { observed in the course of study }\end{array}$ & - & - & {$[28]$} \\
\hline $\begin{array}{l}\text { Palisota hirsuta } \\
\text { extract }\end{array}$ & $\begin{array}{l}\text { Wistar } \\
\text { rats }\end{array}$ & $\begin{array}{l}1 \%, 2 \% \text {, and } 4 \%(w / w) \text { methanol leaf } \\
\text { extract of } P \text {. hirsuta in petroleum jelly; } \\
\text { control: petroleum jelly; } \\
\text { positive control: Cicatrin }{ }^{\circledR} \text { powder } \\
\text { (Neomycin Sulphate, Bacitracin Zinc); } \\
\text { treatment: once daily for } 10 \text { days }\end{array}$ & $\begin{array}{l}4 \%(w / w) \text { extract showed the } \\
\text { highest wound breaking strength }\end{array}$ & - & - & [29] \\
\hline
\end{tabular}


- Table 1 Continued

\begin{tabular}{|c|c|c|c|c|c|c|}
\hline Herbs & Animals & Pharmacological data & Effect & $\begin{array}{l}\text { Mechanism } \\
\text { of action }\end{array}$ & $\begin{array}{l}\text { Anti- } \\
\text { microbial } \\
\text { activity }\end{array}$ & Ref \\
\hline $\begin{array}{l}\text { Plumbago } \\
\text { zeylanica, Datura } \\
\text { stramonium, } \\
\text { Argemone } \\
\text { mexicana extract }\end{array}$ & $\begin{array}{l}\text { Wistar } \\
\text { rats }\end{array}$ & $\begin{array}{l}2 \% \text { and } 5 \% \text { polyherbal formulation } \\
\text { (methanolic extracts of } P \text {. zeylanica, } \\
\text { D.stramonium, } A \text {. mexicana in ratio } \\
4: 4: 2 \text { ) in carbopol-940 gels; } \\
\text { control } 1 \text { : untreated; } \\
\text { negative control: gel base; } \\
\text { positive control: } 5 \% \text { povidone iodine } \\
\text { ointment; } \\
\text { treatment: } 250 \mathrm{mg} \text {, once daily for } \\
9 \text { days }\end{array}$ & $\begin{array}{l}\text { the high rate of wound contraction, } \\
\text { early epithelialization period, and } \\
\text { increased wound breaking strength }\end{array}$ & $\begin{array}{l}\text { antimicro- } \\
\text { bial activity }\end{array}$ & $\begin{array}{l}\text { S. aureus; } \\
\text { B. subtilis; } \\
\text { E. coli; } \\
\text { P. aerugi- } \\
\text { nosa }\end{array}$ & [30] \\
\hline $\begin{array}{l}\text { Pterolobium } \\
\text { hexapetalum } \\
\text { extract }\end{array}$ & $\begin{array}{l}\text { Wistar } \\
\text { rats }\end{array}$ & $\begin{array}{l}2.5 \% \text { and } 5 \%(\mathrm{w} / \mathrm{w}) \text { methanol extract } \\
\text { in ointment; } \\
\text { control: ointment base; } \\
\text { positive control: Neomycin } 5 \%(\mathrm{w} / \mathrm{w}) \text {; } \\
\text { treatment: once a day for } 10 \text { days }\end{array}$ & $\begin{array}{l}\text { tensile strength of wound treated } \\
\text { with } 5 \% \text { ointment comparable to } \\
\text { that of neomycin ointment }\end{array}$ & - & - & [31] \\
\hline $\begin{array}{l}\text { Punica } \\
\text { granatum peel } \\
\text { and pulp }\end{array}$ & $\begin{array}{l}\text { Wistar } \\
\text { rats }\end{array}$ & $\begin{array}{l}\text { hydroalcoholic extract of pomegran- } \\
\text { ate peel/hydroalcoholic extract of } \\
\text { pomegranate pulp/peel + pulp; } \\
\text { control: Eucerin; } \\
\text { positive control: phenytoin; } \\
\text { treatment: after wound establishment } \\
\text { (14 days), twice a day for } 14 \text { days }\end{array}$ & $\begin{array}{l}\text { peel significantly improved the } \\
\text { wound healing process, whereas the } \\
\text { pulp showed no promising effects }\end{array}$ & - & - & [32] \\
\hline $\begin{array}{l}\text { Salvadora persica } \\
\text { extracts }\end{array}$ & $\begin{array}{l}\text { Wistar } \\
\text { rats }\end{array}$ & $\begin{array}{l}\text { carbopol gel containing } 1 \% \\
\text { methanolic extract of S. persica; } \\
\text { control 1: untreated group; } \\
\text { control 2: carbapol gel; } \\
\text { positive control: betadine; } \\
\text { treatment: } 16 \text { days }\end{array}$ & $\begin{array}{l}\text { higher rate of contraction and re- } \\
\text { duced the period of epithelialization }\end{array}$ & $\begin{array}{l}\text { antimicro- } \\
\text { bial activity }\end{array}$ & $\begin{array}{l}\text { C. per- } \\
\text { fringens, } \\
\text { C. albi- } \\
\text { cans, } \\
\text { P. aerogi- } \\
\text { nosa, } \\
\text { S. aureus }\end{array}$ & [33] \\
\hline $\begin{array}{l}\text { Sesamum Indicum } \\
\text { extract }\end{array}$ & $\begin{array}{l}\text { Wistar } \\
\text { rats }\end{array}$ & $\begin{array}{l}\text { ethosomal vesicles with S. Indicum } \\
\text { seed extract in gel base; } \\
\text { control: ointment base; } \\
\text { positive control: povidone iodine } \\
\text { ointment; } \\
\text { treatment: once a daily for } 10 \text { days }\end{array}$ & $\begin{array}{l}\text { tensile strength of skin was similar } \\
\text { to that of standard treated group }\end{array}$ & - & - & [34] \\
\hline $\begin{array}{l}\text { Sida rhombifolia } \\
\text { extract }\end{array}$ & $\begin{array}{l}\text { albino } \\
\text { mice }\end{array}$ & $\begin{array}{l}80 \% \text { ethanolic leaves extract ointment } \\
\text { and water preparations; } \\
\text { control: untreated group; } \\
\text { control negative: ointment base; } \\
\text { positive control: povidone iodine; } \\
\text { treatment: } 10 \text { days }\end{array}$ & $\begin{array}{l}\text { significant wound closure for all } \\
\text { ointment and water formulations }\end{array}$ & - & - & [35] \\
\hline
\end{tabular}

\section{Mechanism of Action of Herbs Used for Treatment of Wounds}

Many herbal products can be successfully used in the treatment of wounds owing to various mechanisms inducing healing and regeneration of the skin such as antimicrobial, anti-inflammatory, and antioxidant activities ( $\bullet$ Fig. 2 ).

\section{Antimicrobial activity of herbal products}

Wound infection is probably the most common reason for impaired wound healing. Pathogens including Staphylococcus aureus, Streptococcus pyogenes, Corynebacterium sp., Escherichia coli, and Pseudomonas aeruginosa are the primary causes of delayed healing and infection in acute wounds [84]. Therefore, topical antimicrobial therapy is one of the most important methods of wound care. An ideal agent for prevention and control of wound infection should directly destroy the pathogens as well as reduce local inflammation and tissue destruction. The use of herbal products for the treatment of wounds provides such opportunities ( $\sim$ Tables 1 to 3 ). The hydroalchoholic extracts of Althaea officinalis [37] and Angelica dahurica and ethanolic extract of Rheum officinale alone and in a 1:1 combination [39]; the methanolic extracts of henna, pomegranate, and myrrh alone or in a combination at a total concentration of $15 \%(\mathrm{w} / \mathrm{w})$ in hydrophilic ointments [24]; $2 \%$ and $5 \%$ polyherbal formulation with methanolic extracts of Plumbago zeylanica, Datura stramonium, and Argemone mexicana (in ratio a 4:4:2) in carbopol-940 gels [30]; $1 \%$ methanolic 
- Table 2 Herbs used for treatment of excision wounds, animal-based studies.

\begin{tabular}{|c|c|c|c|c|c|c|}
\hline Herbs & Animals & Pharmacological data & Effect & $\begin{array}{l}\text { Mechanism } \\
\text { of action }\end{array}$ & $\begin{array}{l}\text { Anti- } \\
\text { microbial } \\
\text { activity }\end{array}$ & Ref \\
\hline $\begin{array}{l}\text { Achyranthes } \\
\text { aspera extract }\end{array}$ & Wistar rats & $\begin{array}{l}10 \%(w / w) \text { ethanolic extracts in ointment; } \\
\text { control: ointment base; } \\
\text { positive control: } 5 \% \text { povidone iodine } \\
\text { ointment; } \\
\text { treatment: twice a day for } 15 \text { days }\end{array}$ & $\begin{array}{l}\text { enhanced wound contraction and } \\
\text { epithelization period }\end{array}$ & - & - & [13] \\
\hline $\begin{array}{l}\text { Aegle marmelos, } \\
\text { Mucuna pruriens } \\
\text { extract }\end{array}$ & Wistar rats & $\begin{array}{l}\text { hydrogel with } 2.5 \% \text { ethyl acetate/metha- } \\
\text { nolic/aqueous } A \text {. marmelos or } M \text {. pruriens } \\
\text { extracts; } \\
\text { control: untreated group; } \\
\text { positive control: Hydroheal; } \\
\text { treatment: once daily for } 12 \text { days }\end{array}$ & $\begin{array}{l}\text { extract hydrogels were found to } \\
\text { be superior to all other treatments } \\
\text { by rapid wound contraction, lesser } \\
\text { number of days required for complete } \\
\text { epithelization }\end{array}$ & - & - & {$[14]$} \\
\hline $\begin{array}{l}\text { Aegle marmelos, } \\
\text { Ocimum } \\
\text { basilicum extract }\end{array}$ & Wistar rats & $\begin{array}{l}5 \%(w / w) \text { ethanolic extract of leaves of } \\
\text { A.marmelos/O. basilicum in ointment; } \\
\text { control: untreated group; } \\
\text { positive control: } 5 \% \text { povidone iodine } \\
\text { ointment; } \\
\text { treatment: once a day for } 15 \text { days }\end{array}$ & $\begin{array}{l}\text { A. marmelos extract have better } \\
\text { wound healing effect than extract } \\
\text { of } O \text {. basilicum; } \\
\text { A. marmelos extract showed faster rate } \\
\text { of healing when compared with drug }\end{array}$ & - & - & [36] \\
\hline $\begin{array}{l}\text { Agave americana } \\
\text { extract }\end{array}$ & Wistar rats & $\begin{array}{l}5 \% \text { and } 10 \% \text { ointment with hydroalcoholic } \\
\text { A. americana leaf extract; } \\
\text { control: ointment base; } \\
\text { positive control: Soframycin ointment; } \\
\text { treatment: once daily for } 16 \text { days }\end{array}$ & $\begin{array}{l}\text { improved wound healing activity; } \\
\text { rate of epithelialization was almost } \\
\text { comparable to Soframycin; } \\
\text { increase in tensile strength }\end{array}$ & - & - & {$[15]$} \\
\hline $\begin{array}{l}\text { Althaea } \\
\text { officinalis } \\
\text { extract }\end{array}$ & Wistar rats & $\begin{array}{l}\text { hydroalchoholic extract; } \\
\text { control: untreated group; } \\
\text { positive control: zinc oxide ointment; } \\
\text { treatment: } 0.5 \mathrm{~g} \text {, once a day for } 21 \text { days }\end{array}$ & $\begin{array}{l}\text { significantly increased wound healing } \\
\text { percent }\end{array}$ & $\begin{array}{l}\text { antimicrobial } \\
\text { activity }\end{array}$ & $\begin{array}{l}\text { S. aureus, } \\
\text { L. mono- } \\
\text { cytogenes }\end{array}$ & [37] \\
\hline $\begin{array}{l}\text { Aloe vera, } \\
\text { Commiphora } \\
\text { myrrha, } \\
\text { Boswellia carteri } \\
\text { extracts }\end{array}$ & Wistar rats & $\begin{array}{l}10 \% \text { and } 40 \% \text { extracts in ratio } 1: 1: 1 \text { in } \\
\text { ointment; } \\
\text { control 1: untreated group; } \\
\text { control } 2 \text { : ointment base; } \\
\text { positive control: tetracycline ointment; } \\
\text { treatment: every day for } 21 \text { days }\end{array}$ & $\begin{array}{l}40 \% \text { ointment showed significant heal- } \\
\text { ing effect in comparison to the control, } \\
\text { tetracycline, and paste base groups }\end{array}$ & - & - & {$[38]$} \\
\hline $\begin{array}{l}\text { Andrographis } \\
\text { paniculata } \\
\text { extract }\end{array}$ & Wistar rats & $\begin{array}{l}\text { A. paniculata methanolic extracts (100 mg/ } \\
\mathrm{kg} / 200 \mathrm{mg} / \mathrm{kg} / 400 \mathrm{mg} / \mathrm{kg}) ; \\
\text { control: untreated group; } \\
\text { positive control: } 1 \% \text { Framycetin sulphate } \\
\text { cream; } \\
\text { treatment: once a day till complete of } \\
\text { epithelization }\end{array}$ & $\begin{array}{l}\text { extract was found to have greater } \\
\text { wound healing activity and to increase } \\
\text { the percentage wound concentration } \\
\text { and period of epithelization }\end{array}$ & $\begin{array}{l}\text { antifungal } \\
\text { activity }\end{array}$ & C. albicans & [18] \\
\hline $\begin{array}{l}\text { Angelica } \\
\text { dahurica, } \text { Rheum } \\
\text { officinale extract }\end{array}$ & $\begin{array}{l}\text { Sprague- } \\
\text { Dawley } \\
\text { rats }\end{array}$ & $\begin{array}{l}\text { A. dahurica extract, } R \text {. officinale extract alone } \\
\text { and in combination } 1: 1 ; \\
\text { control: saline; } \\
\text { positive control: Biomycin; } \\
\text { treatment: } 1 \mu \mathrm{L} / \mathrm{mm}^{2} \text { daily for } 21 \text { days }\end{array}$ & $\begin{array}{l}\text { wound contraction mixed extracts } \\
\text { group was significantly higher than } \\
\text { that in control and biomycin groups }\end{array}$ & $\begin{array}{l}\text { anti- } \\
\text { inflammatory } \\
\text { activity }\end{array}$ & S. aureus & [39] \\
\hline $\begin{array}{l}\text { Anredera } \\
\text { cordifolia extract }\end{array}$ & $\begin{array}{l}\text { Guinea } \\
\text { pigs }\end{array}$ & $\begin{array}{l}\text { ethanolic extract of binahong (A. cordifolia) } \\
\text { leaves at concentrations } \\
\text { of } 10 \%, 20 \% \text {, and } 40 \% \text {; } \\
\text { negative control: distilled water; } \\
\text { positive control: povidone iodine } 10 \% \text {; } \\
\text { treatment: twice daily for } 15 \text { days }\end{array}$ & $\begin{array}{l}\text { groups treated with ethanolic extract of } \\
\text { binahong leaves at concentrations of } \\
20 \% \text { and } 40 \% \text { experienced better } \\
\text { wound healing activity than negative } \\
\text { and positive controls }\end{array}$ & - & - & [40] \\
\hline $\begin{array}{l}\text { Archidium } \\
\text { ohioense oil }\end{array}$ & Wistar rats & $\begin{array}{l}\text { A. ohioense oil ( } 0.5 \text { and } 1.0 \mathrm{mg} / \mathrm{kg} \text { bwt); } \\
\text { control: untreated group; } \\
\text { positive control: gentamicin; } \\
\text { treatment: once daily for } 21 \text { days }\end{array}$ & $\begin{array}{l}\text { enhanced wound breaking strength } \\
\text { and contraction rate, tissue collagen } \\
\text { formation, and early epithelization } \\
\text { period }\end{array}$ & - & - & {$[19]$} \\
\hline
\end{tabular}


- Table 2 Continued

\begin{tabular}{|c|c|c|c|c|c|c|}
\hline Herbs & Animals & Pharmacological data & Effect & $\begin{array}{l}\text { Mechanism } \\
\text { of action }\end{array}$ & $\begin{array}{l}\text { Anti- } \\
\text { microbial } \\
\text { activity }\end{array}$ & Ref \\
\hline $\begin{array}{l}\text { Arnebia } \\
\text { euchroma } \\
\text { extract }\end{array}$ & Rats & $\begin{array}{l}\text { 10\% A. euchroma gel; } \\
\text { control 1: saline; } \\
\text { control 2: carboxymethyl cellulose gel; } \\
\text { treatment: once a day for } 14 \text { days }\end{array}$ & reduction of wound surface & - & - & [41] \\
\hline $\begin{array}{l}\text { Bauhinia } \\
\text { tomentosa } \\
\text { extract }\end{array}$ & Wistar rats & $\begin{array}{l}\text { extract alone, Emu oil alone, combination of } \\
\text { extract and Emu oil; } \\
\text { control: vaseline alone; } \\
\text { positive control: soframycin ointment; } \\
\text { treatment: } 2 \mathrm{~g} / 2 \mathrm{ml} \text {, once a day for } 21 \text { days }\end{array}$ & $\begin{array}{l}\text { Emu oil with extract showed more } \\
\text { significant results when compared } \\
\text { to soframycin ointment }\end{array}$ & - & - & [42] \\
\hline $\begin{array}{l}\text { Boerhavia diffusa } \\
\text { extract }\end{array}$ & Wistar rats & $\begin{array}{l}10 \% \text { methanol and } 10 \% \text { chloroform extracts } \\
\text { in ointment; } \\
\text { control 1: untreated group; } \\
\text { control 2: ointment base; } \\
\text { positive control: } 5.0 \% \mathrm{w} / \mathrm{w} \text { povidone- } \\
\text { iodine; } \\
\text { treatment: } 500 \mathrm{mg} \text {, once a day for } 14 \text { days }\end{array}$ & $\begin{array}{l}\text { efficacy of methanol extract ointments } \\
\text { to heal wounds was comparable with } \\
\text { that of the standard drug }\end{array}$ & - & - & [43] \\
\hline $\begin{array}{l}\text { Centella asiatica } \\
\text { extract }\end{array}$ & $\begin{array}{l}\text { New } \\
\text { Zealand } \\
\text { rabbits }\end{array}$ & $\begin{array}{l}40 \%, 10 \%, 2.5 \%(\mathrm{w} / \mathrm{w}) \text { methanol fraction of } \\
\text { the etract in aqueous cream; } \\
\text { control 1: no treatment; } \\
\text { control 2: blank aqueous cream; } \\
\text { positive control: solcoseryl jelly } 10 \% \text {; } \\
\text { treatment: twice daily }(20 \mathrm{mg}) \text { until the } \\
\text { wounds completely healed }\end{array}$ & $\begin{array}{l}\text { extracts showed comparable results to } \\
\text { the positive control; } \\
\text { methanol fraction of the extract } \\
\text { induced collagen synthesis }\end{array}$ & - & - & [44] \\
\hline $\begin{array}{l}\text { Chromolaena } \\
\text { odorata extract }\end{array}$ & Wistar rats & $\begin{array}{l}2.5 \%, 5 \%, 7.5 \%(\mathrm{w} / \mathrm{w}) \text { aqueous and } \\
\text { ethanolic extracts in petroleum jelly; } \\
\text { control: petroleum jelly; } \\
\text { positive control: } 5 \% \text { povidone-iodine } \\
\text { ointment; } \\
\text { treatment: } 20 \text { days }\end{array}$ & $\begin{array}{l}5 \% \text { extract-treated groups exhibited a } \\
\text { faster reduction in wound area com- } \\
\text { pared to control and treated groups }\end{array}$ & - & - & [45] \\
\hline $\begin{array}{l}\text { Croton } \\
\text { bonplandianum } \\
\text { extract }\end{array}$ & Wistar rats & $\begin{array}{l}\text { herbal preparations from leaf, fruit and latex } \\
\text { of } C \text {. bonplandianum and } \alpha \text {-tocopherol; } \\
\text { control: untreated group }\end{array}$ & $\begin{array}{l}\text { increased levels of collagen content } \\
\text { and wound contraction rate }\end{array}$ & $\begin{array}{l}\text { antioxidant } \\
\text { activity }\end{array}$ & - & [46] \\
\hline $\begin{array}{l}\text { Curcuma longa, } \\
\text { Eclipta alba, } \\
\text { Tridax procum- } \\
\text { bens extract }\end{array}$ & Wistar rats & $\begin{array}{l}\text { poly herbal formulation with } 5 \% \text { and } 10 \% \text {; } \\
\text { control: gel base; } \\
\text { positive control: Aloe vera ( } 90 \% \text { ) gel; } \\
\text { treatment: once a day for } 22 \text { days }\end{array}$ & $\begin{array}{l}\text { significantly reduced period of } \\
\text { epethelization as compared with } \\
\text { control group }\end{array}$ & - & - & [23] \\
\hline $\begin{array}{l}\text { Datura } \\
\text { Stramonium } \\
\text { extract }\end{array}$ & Wistar rats & $\begin{array}{l}10 \%(\mathrm{w} / \mathrm{w}) \text { hydro-alcoholic extract in } \\
\text { ointment; } \\
\text { control: ointment base; } \\
\text { positive control: povidone-iodine ointment; } \\
\text { treatment: } 16 \text { days }\end{array}$ & $\begin{array}{l}\text { extract ointment showed significant } \\
\text { wound healing activity comparable } \\
\text { to that of the standard drug }\end{array}$ & - & - & [47] \\
\hline $\begin{array}{l}\text { Enicostema } \\
\text { littorale extract }\end{array}$ & Wistar rats & $\begin{array}{l}15 \%(w / w) \text { ethanolic leaf extract in ointment } \\
\text { and its active constituent } 3 \% \\
\text { (w/w) pure Swertiamarin in ointment; } \\
\text { control: ointment base; } \\
\text { treatment: once a day for } 15 \text { days }\end{array}$ & $\begin{array}{l}\text { ethanolic extract and Swertiamarin } \\
\text { ointment resulted in decrease of the } \\
\text { wound area; } \\
\text { Swertiamarin-treated group had a high } \\
\text { percentage of wound contraction score }\end{array}$ & - & - & [48] \\
\hline $\begin{array}{l}\text { Euphorbia } \\
\text { tirucalli extract }\end{array}$ & $\begin{array}{l}\text { Albino } \\
\text { mice }\end{array}$ & $\begin{array}{l}50 \%, 75 \% \text {, and } 100 \% \text { E. tirucalli latex } \\
\text { (milk bush); } \\
\text { control: destill water; } \\
\text { positive control: povidone-iodine; } \\
\text { treatment: } 6 \text { days }\end{array}$ & $\begin{array}{l}\text { positive wound healing effect as mani- } \\
\text { fested by the formation of scar tissue, } \\
\text { which effectively led to wound closure }\end{array}$ & - & - & [49] \\
\hline $\begin{array}{l}\text { Euterpe oleracea } \\
\text { extracts }\end{array}$ & $\begin{array}{l}\text { Sprague } \\
\text { Dawley } \\
\text { rats }\end{array}$ & $\begin{array}{l}1 \%, 3 \%, 5 \% \text { acai berry water extract; } \\
\text { control: ointment base; } \\
\text { positive control: } 2 \% \text { sodium fusidate } \\
\text { ointment; } \\
\text { treatment: } 200 \mu \mathrm{L} \text {, once a day for } 18 \text { days }\end{array}$ & $\begin{array}{l}\text { significantly reduced wound area } \\
\text { at } 6 \text { days after creating the wound and } \\
\text { reepithelization after } 18 \text { days }\end{array}$ & $\begin{array}{l}\text { anti- } \\
\text { inflamatory } \\
\text { activity }\end{array}$ & - & [50] \\
\hline
\end{tabular}


- Table 2 Continued

\begin{tabular}{|c|c|c|c|c|c|c|}
\hline Herbs & Animals & Pharmacological data & Effect & $\begin{array}{l}\text { Mechanism } \\
\text { of action }\end{array}$ & $\begin{array}{l}\text { Anti- } \\
\text { microbial } \\
\text { activity }\end{array}$ & Ref \\
\hline $\begin{array}{l}\text { Falcaria vulgaris } \\
\text { extract }\end{array}$ & Wistar rats & $\begin{array}{l}3 \% \text { aqueous extract of F. vulgaris ointment; } \\
\text { control 1: untreated group; } \\
\text { control 2: Eucerin ointment; } \\
\text { positive control: } 3 \% \text { tetracycline ointment; } \\
\text { treatment: for } 30 \text { days }\end{array}$ & $\begin{array}{l}\text { significant decrease in the levels } \\
\text { of wound area, wound contracture, } \\
\text { hydroxyproline, hexosamine, fibrocyte, } \\
\text { fibroblast }\end{array}$ & - & - & [51] \\
\hline $\begin{array}{l}\text { Glycyrrhiza } \\
\text { glabra extract }\end{array}$ & Guinea Pig & $\begin{array}{l}5 \% \text { and } 10 \%(w / w) \text { G. glabra etract in cream; } \\
\text { control: untreated group; } \\
\text { positive control: } 1 \% \text { phenytoin; } \\
\text { treatment: once a day for } 12 \text { days }\end{array}$ & $\begin{array}{l}\text { increased epidermal formation, } \\
\text { collagen deposition, and neovascu- } \\
\text { larization, decreased acute inflamma- } \\
\text { tion; } \\
10 \% \text { cream was more effective than } 5 \% \\
\text { cream }\end{array}$ & - & - & [52] \\
\hline $\begin{array}{l}\text { Glycyrrhiza } \\
\text { glabra, Nerium } \\
\text { indicum extract }\end{array}$ & Wistar rats & $\begin{array}{l}\text { Honey, Ghee, G. glabra and N. indicum alone } \\
\text { and a combination; } \\
\text { control: untreated group; } \\
\text { treatment: } 500 \text { mg once a day for } 16 \text { days }\end{array}$ & $\begin{array}{l}\text { rapid epithelization and better } \\
\text { remodeling }\end{array}$ & - & - & [53] \\
\hline $\begin{array}{l}\text { henna, pome- } \\
\text { granate and } \\
\text { myrrh extracts }\end{array}$ & Wistar rats & $\begin{array}{l}\text { extracts alone or in a combination } \\
\text { with total concentration of } 15 \% \mathrm{w} / \mathrm{w} \\
\text { in hydrophilic ointments; } \\
\text { negative control: base ointment; } \\
\text { positive control: gentamycin ointment; } \\
\text { treatment: twice daily for } 24 \text { days }\end{array}$ & $\begin{array}{l}\text { the blended formulation showed the } \\
\text { highest increase in the percent of } \\
\text { wound contraction; } \\
\text { decrease in the epithelization period } \\
\text { comparable to the standard ointment }\end{array}$ & $\begin{array}{l}\text { antimicrobial } \\
\text { activity }\end{array}$ & $\begin{array}{l}\text { C. albicans, } \\
\text { S. aureus, } \\
\text { E. coli }\end{array}$ & [24] \\
\hline $\begin{array}{l}\text { Hippophae } \\
\text { rhamnoides } \\
\text { extract }\end{array}$ & $\begin{array}{l}\text { Sprague- } \\
\text { Dawley } \\
\text { rats }\end{array}$ & $\begin{array}{l}\text { hydrogel containing } 100 \text { mg of powdered } \\
\text { extract; } \\
\text { control 1: sterile gauze; } \\
\text { control 2: hydrogel only; } \\
\text { control 3: hydrogel with } 100 \text { mg ascorbic } \\
\text { acid; } \\
\text { treatment: appliedweekly for } 21 \text { days }\end{array}$ & significantly reduced wound size & - & - & [54] \\
\hline $\begin{array}{l}\text { Hydrolea } \\
\text { zeylanica extract }\end{array}$ & Wistar rats & $\begin{array}{l}5 \%(w / w) \text { aqueous and methanol extract in } \\
\text { ointment; } \\
\text { negative control: ointment base; } \\
\text { positive control: povidone iodine } 5 \% \\
(\mathrm{w} / \mathrm{w}) \text {; treatment: until wound is completely } \\
\text { healed }\end{array}$ & $\begin{array}{l}\text { increased rate of wound contraction, } \\
\text { decreased period of epithelization and } \\
\text { increased skin breaking strength }\end{array}$ & - & - & [25] \\
\hline $\begin{array}{l}\text { Justicia tranque- } \\
\text { bariensis, Aloe } \\
\text { vera, Curcuma } \\
\text { longa extracts }\end{array}$ & Wistar rats & $\begin{array}{l}\text { lotions with } 10 \% \text { and } 20 \% \text { ethanolic } \\
\text { extracts; } \\
\text { control: untreated group; } \\
\text { positive control: Soframycin; } \\
\text { treatment: once daily for } 15 \text { days }\end{array}$ & $\begin{array}{l}\text { complete wound healing was observed } \\
\text { with both lotions in } 15 \text { days } \\
\text { as that of Soframycin ointment }\end{array}$ & $\begin{array}{l}\text { antimicrobial } \\
\text { activity }\end{array}$ & $\begin{array}{l}\text { E. coli, } \\
\text { K. pneumo- } \\
\text { niae, } \\
\text { S. aureus, } \\
\text { B. subtilis }\end{array}$ & [55] \\
\hline $\begin{array}{l}\text { Lawsonia inermis } \\
\text { extract }\end{array}$ & $\begin{array}{l}\text { Sprague } \\
\text { Dawley } \\
\text { rats }\end{array}$ & $\begin{array}{l}\text { Lawsonia inermis extract; } \\
\text { control 1: saline; } \\
\text { control 2: hydrogel; } \\
\text { positive control: Silver Zinc sulfadiazine; } \\
\text { treatment: twice a day for } 15 \text { days }\end{array}$ & $\begin{array}{l}\text { the wound size reduction and rate } \\
\text { of epithelialiazation; } \\
\text { significant increase in collagen and } \\
\text { fibroblasts, reduced inflammatory cell } \\
\text { number }\end{array}$ & - & - & [56] \\
\hline $\begin{array}{l}\text { Linum } \\
\text { usitatissimum } \\
\text { extract }\end{array}$ & Wistar rats & $\begin{array}{l}5 \% \text { and } 10 \% \text { L. usitatissimum (LU) gel; } \\
\text { control 1: untreated group; } \\
\text { control } 2 \text { : gel base; } \\
\text { treatment: once a day for } 15 \text { days }\end{array}$ & $\begin{array}{l}\text { significantly higher wound areas, } \\
\text { collagen bundle synthesis }\end{array}$ & - & - & [57] \\
\hline $\begin{array}{l}\text { Macroptilium } \\
\text { atropurpureum } \\
\text { extract }\end{array}$ & Wistar rats & $\begin{array}{l}\text { ointment of } 10 \%(w / w) \text { petroleum ether and } \\
10 \%(w / w) \text { aqueous extracts; } \\
\text { control: untreated group; } \\
\text { positive control: } 15 \text { Silver sulfadiazine; } \\
\text { treatment: until complete healing }\end{array}$ & $\begin{array}{l}\text { wound healing effect comparable } \\
\text { to standard drug }\end{array}$ & - & - & [27] \\
\hline
\end{tabular}


- Table 2 Continued

\begin{tabular}{|c|c|c|c|c|c|c|}
\hline Herbs & Animals & Pharmacological data & Effect & $\begin{array}{l}\text { Mechanism } \\
\text { of action }\end{array}$ & $\begin{array}{l}\text { Anti- } \\
\text { microbial } \\
\text { activity }\end{array}$ & Ref \\
\hline $\begin{array}{l}\text { Momordica } \\
\text { charantia, } \\
\text { Pongamia } \\
\text { glabra, Piper } \\
\text { nigrum extracts }\end{array}$ & Wistar rats & $\begin{array}{l}10 \% \text { and } 15 \% \text { alcoholic and aqueous } \\
\text { extracts of } M \text {. charantia } 1: 1 \text { in ointment, } \\
10 \% \text { and } 15 \% \text { alcoholic and aqueous } \\
\text { extracts of } P \text {. glabra } 1: 1 \text { in ointment, } 10 \% \\
\text { and } 15 \% \text { alcoholic and aqueous extracts } \\
\text { of } P . \text { nigrum } 1: 1 \text { in ointment, combination of } \\
\text { all extracts ( } 5 \% \text { each) in ointment; } \\
\text { control: ointment base; } \\
\text { positive control: Povidone iodine ointment; } \\
\text { treatment: once daily for } 10 \text { days }\end{array}$ & $\begin{array}{l}\text { decreased wound area, no mortality } \\
\text { observed in the course of study }\end{array}$ & - & - & [58] \\
\hline Nigella sativa oil & Wistar rats & $\begin{array}{l}\text { honey, } N \text {. sativa seed oil and their } \\
\text { combination } 1: 1 \text { ratio; } \\
\text { control: lanolin; } \\
\text { positive control: phenytoin cream; } \\
\text { treatment: } 20 \text { days }\end{array}$ & $\begin{array}{l}\text { wound surface areas in the mix group } \\
\text { were significantly lower than in the } \\
\text { other groups followed by the phe- } \\
\text { nytoin, honey, N. sativa, and control } \\
\text { groups }\end{array}$ & - & - & [59] \\
\hline $\begin{array}{l}\text { Nigella sativa } \\
\text { seed powder }\end{array}$ & Wistar rats & $\begin{array}{l}\text { N. sativa seed powder; } \\
\text { control: untreated group; } \\
\text { positive control: Amoxicillin; } \\
\text { treatment: } 500 \mathrm{mg} \text {, once a day till complete } \\
\text { epithelialization up to } 14 \text { days }\end{array}$ & $\begin{array}{l}\text { powder has faster recovery rate than } \\
\text { the standard drug }\end{array}$ & - & - & [60] \\
\hline $\begin{array}{l}\text { Nigella sativa, } \\
\text { Hypericum } \\
\text { perforatum } \\
\text { extract }\end{array}$ & Wistar rats & $\begin{array}{l}50 \% \text { N. sativa extract in cream and } 50 \% \\
\text { H. perforatum extract in cream; } \\
\text { control: cream base; } \\
\text { treatment: twice a day for } 14 \text { days }\end{array}$ & $\begin{array}{l}\text { N. sativa cream had more antioxidant } \\
\text { properties than the other treatments; } \\
\text { H. perforatum cream increased epithe- } \\
\text { lialization and granulation }\end{array}$ & - & - & [61] \\
\hline $\begin{array}{l}\text { Plantago } \\
\text { lanceolata } \\
\text { extract }\end{array}$ & Mice & $\begin{array}{l}\text { ointment with } 10 \% \text { and } 20 \% \text { P. lanceolata } \\
\text { extract; } \\
\text { control: untreated group; } \\
\text { control: vaseline; } \\
\text { treatment: } 21 \text { days }\end{array}$ & $\begin{array}{l}\text { both concentrations of } P \text {. lanceolata } \\
\text { extract exhibited positive effects on } \\
\text { wound healing }\end{array}$ & - & - & [62] \\
\hline $\begin{array}{l}\text { Plumbago } \\
\text { zeylanica, Datura } \\
\text { stramonium, } \\
\text { Argemone mexi- } \\
\text { cana extract }\end{array}$ & Wistar rats & $\begin{array}{l}2 \% \text { and } 5 \% \text { polyherbal formulation } \\
\text { (methanolic extracts of } P \text {. zeylanica, } \\
\text { D. stramonium, A. mexicana in ratio } 4: 4: 2 \text { ) in } \\
\text { carbopol- } 940 \text { gels; } \\
\text { control 1: untreated; } \\
\text { negative control: gel base; } \\
\text { positive control: } 5 \% \mathrm{w} / \mathrm{w} \text { povidone iodine } \\
\text { ointment; } \\
\text { treatment: } 500 \mathrm{mg} \text {, once daily until } \\
\text { the complete healing }\end{array}$ & $\begin{array}{l}\text { the high rate of wound contraction, } \\
\text { early epithelialization period, and } \\
\text { increased wound breaking strength }\end{array}$ & $\begin{array}{l}\text { antimicrobial } \\
\text { activity }\end{array}$ & $\begin{array}{l}\text { S. aureus; } \\
\text { B. subtilis; } \\
\text { E.coli; } \\
\text { P. aerugino- } \\
\text { sa }\end{array}$ & [30] \\
\hline $\begin{array}{l}\text { Psorolea } \\
\text { corylifalia, } \\
\text { Achryanthes } \\
\text { aspera extract }\end{array}$ & Wistar rats & $\begin{array}{l}\text { polyherbal ointment with hydrochloric } \\
\text { extracts } 1: 1 \text {; } \\
\text { control: ointment base; } \\
\text { positive control: cipladine; } \\
\text { treatment: once daily for } 14 \text { days }\end{array}$ & $\begin{array}{l}\text { polyherbal ointment produced greater } \\
\text { wound contraction than the other } \\
\text { tested formulations }\end{array}$ & - & - & [63] \\
\hline $\begin{array}{l}\text { Pterolobium } \\
\text { hexapetalum } \\
\text { extract }\end{array}$ & Wistar rats & $\begin{array}{l}2.5 \% \text { and } 5 \%(\mathrm{w} / \mathrm{w}) \text { methanol extract } \\
\text { in ointment; } \\
\text { control: ointment base; } \\
\text { positive control: Neomycin } 5 \%(\mathrm{w} / \mathrm{w}) \text {; } \\
\text { treatment: once a day for } 21 \text { days }\end{array}$ & $\begin{array}{l}\text { the highest wound contraction per- } \\
\text { centage and lowest epithelialization } \\
\text { period of } 5 \% \text { ointment in comparison to } \\
\text { control group }\end{array}$ & - & - & [31] \\
\hline $\begin{array}{l}\text { Punica granatum } \\
\text { extract }\end{array}$ & Wistar rats & $\begin{array}{l}10 \% \text { dried powder of } P \text {. granatum in } \\
\text { ointment; } \\
\text { control: vaseline; } \\
\text { positive control: Fucidin ointment; } \\
\text { treatment: once a day for } 19 \text { days }\end{array}$ & $\begin{array}{l}\text { dry powder promoted healing in } \\
\text { shorter time (13 days) than drugs } \\
\text { (17 days) }\end{array}$ & - & - & [64] \\
\hline
\end{tabular}


- Table 2 Continued

\begin{tabular}{|c|c|c|c|c|c|c|}
\hline Herbs & Animals & Pharmacological data & Effect & $\begin{array}{l}\text { Mechanism } \\
\text { of action }\end{array}$ & $\begin{array}{l}\text { Anti- } \\
\text { microbial } \\
\text { activity }\end{array}$ & Ref \\
\hline $\begin{array}{l}\text { Rheum emodi } \\
\text { etract }\end{array}$ & Rabbits & $\begin{array}{l}10 \% \text { ethanolic, aqueous, petroleum ether } \\
\text { extracts and crude powder; } \\
\text { positive control: povidone-iodine ointment; } \\
\text { treatment: } 12 \text { days }\end{array}$ & $\begin{array}{l}\text { wound healling activity: petroleum } \\
\text { ether extract > aqueous extract }>\text { etha- } \\
\text { nolic extract > crude dust powder > } \\
\text { control group }\end{array}$ & $\begin{array}{l}\text { antibacterial } \\
\text { activity }\end{array}$ & - & {$[65]$} \\
\hline Rosehip oil & Wistar rats & $\begin{array}{l}\text { Rosehip oil; } \\
\text { control: untreated group; } \\
\text { treatment: once daily for } 21 \text { days }\end{array}$ & $\begin{array}{l}\text { wound contracting ability of rosehip oil } \\
\text { was significantly higher when com- } \\
\text { pared to the control group }\end{array}$ & $\begin{array}{l}\text { anti- } \\
\text { inflammatory } \\
\text { activity }\end{array}$ & - & {$[66]$} \\
\hline $\begin{array}{l}\text { Salix acmophylla } \\
\text { extract }\end{array}$ & Rabbits & $\begin{array}{l}5 \% \text { ethanolic and } 5 \% \text { aqueous extract } \\
\text { in ointment (sofr paraffin); } \\
\text { control: untreated group; } \\
\text { treatment: till the wound heals completely }\end{array}$ & $\begin{array}{l}\text { wound closure: ethanolic extract } \\
\text { ( } 14 \text { days })>\text { aqueous extract }(17 \text { days })> \\
\text { control group ( } 20 \text { days })\end{array}$ & $\begin{array}{l}\text { antioxidative } \\
\text { activity }\end{array}$ & - & {$[67]$} \\
\hline $\begin{array}{l}\text { Salvadora } \\
\text { persica extract }\end{array}$ & Wistar rats & $\begin{array}{l}\text { vaseline with } 10 \% \text { (w/w) S. persica extract; } \\
\text { control: vaseline; } \\
\text { positive control: Solcosseryl jelly } 10 \% \text {; } \\
\text { treatment: once daily until the complete } \\
\text { healing of wound }\end{array}$ & $\begin{array}{l}\text { S. persica extract significantly enhanced } \\
\text { acceleration rate of wound enclosure }\end{array}$ & - & - & {$[68]$} \\
\hline $\begin{array}{l}\text { Salvadora } \\
\text { persica extracts }\end{array}$ & Wistar rats & $\begin{array}{l}\text { carbopol gel containing } 1 \% \text { methanolic } \\
\text { extract; } \\
\text { control 1: untreated group; } \\
\text { control 2: carbapol gel; } \\
\text { positive control: betadine; } \\
\text { treatment: } 16 \text { days }\end{array}$ & $\begin{array}{l}\text { higher rate of contraction and reduced } \\
\text { period of epithelialization }\end{array}$ & $\begin{array}{l}\text { antimicrobial } \\
\text { activity }\end{array}$ & $\begin{array}{l}\text { C. perfrin- } \\
\text { gens, } \\
\text { C. albicans, } \\
\text { P. aerogi- } \\
\text { nosa, } \\
\text { S. aureus }\end{array}$ & [33] \\
\hline $\begin{array}{l}\text { Sambucus ebulus } \\
\text { extract }\end{array}$ & Wistar rats & $\begin{array}{l}5 \% \text { methanol extract in ointment; } \\
\text { control: untreated group; } \\
\text { negative control: ointment base; } \\
\text { treatment: once a day for } 12 \text { days }\end{array}$ & $\begin{array}{l}\text { extract improved wound contraction } \\
\text { and closure, reduced the number of } \\
\text { inflammatory cells, increased wound- } \\
\text { healing rate and epithelialization, sig- } \\
\text { nificantly improved collagen formation } \\
\text { and granulation tissue formation }\end{array}$ & - & - & [69] \\
\hline $\begin{array}{l}\text { Satureja } \\
\text { khuzistanica } \\
\text { extract }\end{array}$ & Wistar rats & $\begin{array}{l}\text { S. khuzistanica ethanolic extract and } \\
\text { encapsulated extract of S. khuzistanica } \\
\text { in hydrogel alginate; } \\
\text { control 1: untreated group; } \\
\text { control 2: hydrogel alginate; } \\
\text { treatment: } 22 \text { days }\end{array}$ & $\begin{array}{l}\text { encapsulated extract in hydrogel } \\
\text { alginate may accelerate wound } \\
\text { improvement and increase the rate } \\
\text { of wound healing without scar forma- } \\
\text { tion }\end{array}$ & - & - & {$[70]$} \\
\hline $\begin{array}{l}\text { Schinus } \\
\text { terebinthifolius } \\
\text { oil }\end{array}$ & $\begin{array}{l}\text { C57BL/6 } \\
\text { mice }\end{array}$ & $\begin{array}{l}\text { ointment containing } 10 \% \text { oil; } \\
\text { control: ointment base (lanolin/vaseline } \\
\text { base); } \\
\text { treatment: once a day for } 14 \text { days }\end{array}$ & $\begin{array}{l}\text { oils promoted a reduction in leucocyte } \\
\text { accumulation and in pro-inflammatory } \\
\text { cytokine; } \\
\text { significantly increased the number } \\
\text { of blood vessels and collagen fibers } \\
\text { deposition in comparison to control } \\
\text { group }\end{array}$ & $\begin{array}{l}\text { anti- } \\
\text { inflammatory } \\
\text { activity }\end{array}$ & - & [71] \\
\hline $\begin{array}{l}\text { Scrophularia } \\
\text { striata extract }\end{array}$ & $\begin{array}{l}\text { Sprague- } \\
\text { Dawley } \\
\text { rats }\end{array}$ & $\begin{array}{l}5 \% \text { and } 10 \% \text { S. striata extract; } \\
\text { control 1: untreated group; } \\
\text { control 2: basal cream; } \\
\text { positive control: tetracycline (3\%); } \\
\text { treatment: } 1 \mathrm{ml}, 30 \text { days }\end{array}$ & $\begin{array}{l}\text { significant decrease in the wound area, } \\
\text { alignment of the healing tissue, re-epi- } \\
\text { thelilization and epithelial formation, } \\
\text { enhanced maturity of the collagen fi- } \\
\text { bers and fibroblasts and large capillary- } \\
\text { sized blood vessels }\end{array}$ & - & - & [72] \\
\hline $\begin{array}{l}\text { Sesamum } \\
\text { Indicum extract }\end{array}$ & Wistar rats & $\begin{array}{l}\text { ethosomal vesicles with S. Indicum seed } \\
\text { extract in gel base; } \\
\text { control: ointment base; } \\
\text { positive control: povidone iodine ointment; } \\
\text { treatment: once a day, till the complete } \\
\text { wound healing }\end{array}$ & $\begin{array}{l}\text { increase wound contraction, } \\
\text { period of epithelialization }\end{array}$ & - & - & [34] \\
\hline
\end{tabular}


- Table 2 Continued

\begin{tabular}{|c|c|c|c|c|c|c|}
\hline Herbs & Animals & Pharmacological data & Effect & $\begin{array}{l}\text { Mechanism } \\
\text { of action }\end{array}$ & $\begin{array}{l}\text { Anti- } \\
\text { microbial } \\
\text { activity }\end{array}$ & Ref \\
\hline $\begin{array}{l}\text { Sida rhombifolia } \\
\text { extract }\end{array}$ & $\begin{array}{l}\text { Albino } \\
\text { mice }\end{array}$ & $\begin{array}{l}50 \%, 33 \% \text {, and } 25 \% \text { formulated } 80 \% \\
\text { ethanolic leaves extract ointment and water } \\
\text { preparations; } \\
\text { control: untreated group; } \\
\text { control negative: ointment base; } \\
\text { positive control: Povidone lodine; } \\
\text { treatment: } 15 \text { days }\end{array}$ & $\begin{array}{l}\text { significant wound closure for all } \\
\text { ointment and water formulations }\end{array}$ & - & - & [35] \\
\hline $\begin{array}{l}\text { Stevia } \\
\text { rebaudiana } \\
\text { extract }\end{array}$ & Wistar rats & $\begin{array}{l}\text { 10\% ethanol extract of S. rebaudiana } \\
\text { control 1: untreated group; } \\
\text { control 2: cream base; } \\
\text { positive control: tetracycline ( } 3 \% \text {; } \\
\text { treatment: } 1 \mathrm{~mL} \text {, once a day for } 20 \text { days }\end{array}$ & $\begin{array}{l}\text { significant reduction in the wound area; } \\
\text { improved re-epithelilization and } \\
\text { epithelial formation; } \\
\text { decrease in the total number of cells, } \\
\text { fibrocytes/fibroblasts ratio, neutro- } \\
\text { phils, and lymphocytes and enhanced } \\
\text { number of blood vessels and fibro- } \\
\text { blasts at day } 20\end{array}$ & - & - & [73] \\
\hline $\begin{array}{l}\text { Tridax } \\
\text { procumbens, } \\
\text { Vitex negundo, } \\
\text { Emblica officina- } \\
\text { lis Gaertn } \\
\text { extracts }\end{array}$ & Wistar rats & $\begin{array}{l}\text { polyherbal formulation (aqueous extracts } \\
\text { were mixed in equal proportion and added } \\
\text { to the cream); } \\
\text { control: untreated; } \\
\text { positive control: Cipladine; } \\
\text { treatment: once a day for } 15 \text { days }\end{array}$ & $\begin{array}{l}\text { polyherbal formulation showed rapid } \\
\text { regeneration of skin and wound con- } \\
\text { traction; } \\
\text { proliferation and mobilization } \\
\text { of fibroblast and keratinocytes; } \\
\text { promotion of angiogenesis }\end{array}$ & - & - & [74] \\
\hline $\begin{array}{l}\text { Urtica dioica, } \\
\text { Sambucus ebulus } \\
\text { extracts }\end{array}$ & Wistar rats & $\begin{array}{l}2 \%, 5 \% \text { U. dioica extracts ointment; } \\
2 \%, 5 \% \text { S. ebulus etracts ointment; } \\
2 \%, 5 \% \text { combination of extract ointment; } \\
\text { control: untreated; } \\
\text { negative control: Eucerin; } \\
\text { positive control: phenytoin; } \\
\text { treatment: once a day for } 21 \text { days }\end{array}$ & $\begin{array}{l}\text { ointments with extracts and their com- } \\
\text { bination possess strong wound healing } \\
\text { properties; } \\
\text { the best results were observed with the } \\
\text { S. ebulus ( } 2 \% \text { ) and the combination } 2 \% \\
\text { groups }\end{array}$ & - & - & [75] \\
\hline $\begin{array}{l}\text { Zingiber } \\
\text { zerumbet extract }\end{array}$ & Wistar rats & $\begin{array}{l}5 \% \text { Z. zerumbet ethyl acetate extract; } \\
\text { control: PBS; } \\
\text { positive control: solcoseryl gel; } \\
\text { treatment: once a day for } 14 \text { days }\end{array}$ & $\begin{array}{l}\text { increased wounds closure and } \\
\text { hydroxyproline levels }\end{array}$ & - & - & [76] \\
\hline $\begin{array}{l}\text { Ziziphus } \\
\text { mauritiana } \\
\text { extract }\end{array}$ & Wistar rats & $\begin{array}{l}5 \%(w / w) \text { ethanolic extract in ointment } \\
\text { base; } \\
\text { control: untreated group; } \\
\text { positive control: povidine iodine } 5 \%(w / w) \text {; } \\
\text { treatment: } 2.5 \mathrm{~g} \text { once a day for complete } \\
\text { healing }\end{array}$ & $\begin{array}{l}\text { treatment with extract promoted the } \\
\text { wound contraction and reduced the } \\
\text { days required for epithelization }\end{array}$ & - & - & [77] \\
\hline
\end{tabular}

extract of Salvadora persica incarbopol gel [33]; and 10\% and 20\% ethanolic extracts of Justicia tranquebariensis, Aloe vera, and Curcuma longa in lotions [55] exhibit antibacterial activities against gram-negative (P. aeruginosa, E. coli, Klebsiella pneumoniae) and gram-positive (S. aureus, Bacillus subtilis, S. pyogenes, Listeria monocytogenes, and Clostridium perfringens) bacteria. Moreover, methanolic extract of Andrographis paniculata [18], $1 \%$ methanolic extract of S. persica in carbopol gel [33], and methanolic extracts of henna, pomegranate, and myrrh [24] additionally inhibit Candida albicans growth.

\section{Anti-inflammatory activity of herbal products}

Inflammation at the early phase of wound repair is essential for preventing microbial infection and scavenging of dead cells and cellular debris. Furthermore, it generates proinflammatory mediators such as interleukin (IL-1, IL-6, IL-12), TNF $\alpha$, inducible nitric oxide synthase (iNOS), and chemokines, which play a major role in the inflammation process during wound healing $[3,85]$. Moreover, it was shown that the macrophages with a proinflammatory M1 phenotype are more often found in the early stages of repair, whereas those with anti-inflammatory M2 phenotypes, which are prorepair, are present in the latter stages of wound healing [86]. Therefore, later during the healing process, macrophages expressing anti-inflammatory mediators (such as IL-1 receptor antagonist, decoy IL-1 receptor type II, and IL-10) as well as growth factors (such as TGF $\beta$, VEGF, and IGF1) are present, promoting fibroblast proliferation, ECM synthesis, and angiogenesis [87]. In the final phase of healing, macrophages also regulate ECM content and remodeling by secretion of proteases and their inhibitors such as MMPs and tissue inhibitors of metalloproteinase (TIMPs) [88]. MMPs catalyze the hydrolysis of major ECM molecules (including collagen, elastin, laminin, and fibronectin) as well as the 
- Table 3 Herbs used for treatment of dead space wounds, animal-based studies.

\begin{tabular}{|c|c|c|c|c|c|c|}
\hline Herbs & Animals & Pharmacological data & Effect & $\begin{array}{l}\text { Mechanism } \\
\text { of action }\end{array}$ & $\begin{array}{l}\text { Anti- } \\
\text { microbial } \\
\text { activity }\end{array}$ & Ref \\
\hline $\begin{array}{l}\text { Aegle marme- } \\
\text { los, Mucuna } \\
\text { pruriens extract }\end{array}$ & $\begin{array}{l}\text { Wistar } \\
\text { rats }\end{array}$ & $\begin{array}{l}\text { hydrogel with } 2.5 \% \text { ethyl acetate/metha- } \\
\text { nolic/aqueous } A \text {. marmelos or } M \text {. pruriens } \\
\text { extracts; } \\
\text { control: untreated group; } \\
\text { positive control: Hydroheal; } \\
\text { treatment: once daily for } 12 \text { days }\end{array}$ & $\begin{array}{l}\text { extract hydrogels were found to be } \\
\text { superior to all other treatments by } \\
\text { significant increase in hydroxyproline } \\
\text { content }\end{array}$ & - & - & [14] \\
\hline $\begin{array}{l}\text { Alpinia galanga } \\
\text { extract }\end{array}$ & $\begin{array}{l}\text { Wistar } \\
\text { rats }\end{array}$ & $\begin{array}{l}2 \% \text { and } 5 \%(\mathrm{w} / \mathrm{w}) \text { petroleum ether and } \\
\text { ethanolic extract in ointment; } \\
\text { positive control: povidone iodine } \\
\text { ointment; } \\
\text { treatment: once a day for } 9 \text { days }\end{array}$ & $\begin{array}{l}\text { ethanol extract showed significantly } \\
\text { faster wound healing; } \\
\text { hydroxyproline content and protein } \\
\text { content were significantly higher in } \\
\text { both ethanolic extract group }\end{array}$ & $\begin{array}{l}\text { antioxidant } \\
\text { activity }\end{array}$ & - & [17] \\
\hline $\begin{array}{l}\text { Archidium } \\
\text { ohioense oil }\end{array}$ & $\begin{array}{l}\text { Wistar } \\
\text { rats }\end{array}$ & $\begin{array}{l}\text { A. ohioense oil ( } 0.5 \text { and } 1.0 \mathrm{mg} / \mathrm{kg} \text { bwt); } \\
\text { control: untreated group; } \\
\text { positive control: gentamicin } 0.5 \mathrm{mg} / \mathrm{kg} \\
\text { bwt and } 1.0 \mathrm{mg} / \mathrm{kg} \text { bwt; } \\
\text { treatment: once daily for } 10 \text { days }\end{array}$ & $\begin{array}{l}\text { wound breaking strength and con- } \\
\text { traction rate, tissue collagen forma- } \\
\text { tion, and early epithelization period }\end{array}$ & - & - & [19] \\
\hline $\begin{array}{l}\text { henna, } \\
\text { pomegranate } \\
\text { and myrrh } \\
\text { extracts }\end{array}$ & $\begin{array}{l}\text { Wistar } \\
\text { rats }\end{array}$ & $\begin{array}{l}\text { henna, pomegranate, and myrrh metha- } \\
\text { nolic extract alone or in a combination } \\
\text { at a total concentration of } 15 \%(\mathrm{w} / \mathrm{w}) \text { in } \\
\text { hydrophilic ointments; } \\
\text { negative control: ointment base; } \\
\text { positive control: gentamycin ointment; } \\
\text { treatment: twice daily for } 24 \text { days }\end{array}$ & $\begin{array}{l}\text { the blended formulation showed the } \\
\text { highest increase in the percent of } \\
\text { wound contraction and } \\
\text { decrease in the epithelization period } \\
\text { comparable with standard ointment }\end{array}$ & $\begin{array}{l}\text { antimicro- } \\
\text { bial activity }\end{array}$ & $\begin{array}{l}\text { C. albi- } \\
\text { cans, } \\
\text { S. aureus, } \\
\text { E. coli }\end{array}$ & [24] \\
\hline $\begin{array}{l}\text { Martynia } \\
\text { annua, } \\
\text { Tephrosia } \\
\text { purpurea } \\
\text { extracts }\end{array}$ & $\begin{array}{l}\text { Wistar } \\
\text { rats }\end{array}$ & $\begin{array}{l}\text { ointment with } 5 \%(\mathrm{w} / \mathrm{w}) \text { methanol frac- } \\
\text { tion of M. annua (MAF-C) and ethyl acetate } \\
\text { fraction of T. purpurea (TPF-A); } \\
\text { ointments with pongamol }(0.2 \text { and } 0.5 \% \\
\mathrm{w} / \mathrm{w}) \text {; } \\
\text { ointments with luteolin }(0.2 \text { and } 0.5 \% \\
\text { w/w); } \\
\text { control: ointment base; } \\
\text { positive control: } 5 \% \text { povidone iodine } \\
\text { ointment; } \\
\text { treatment: twice a day for } 9 \text { days }\end{array}$ & $\begin{array}{l}5 \% \mathrm{w} / \mathrm{w} \text { ointment of TPF-A and } \\
\text { MAF-C fractions were more effective } \\
\text { than isolated flavonoids in wound } \\
\text { healing; } \\
\text { significantly increased the hydroxy- } \\
\text { proline and protein contents }\end{array}$ & - & - & [78] \\
\hline $\begin{array}{l}\text { Pterolobium } \\
\text { hexapetalum } \\
\text { extract }\end{array}$ & $\begin{array}{l}\text { Wistar } \\
\text { rats }\end{array}$ & $\begin{array}{l}2.5 \% \text { and } 5 \%(\mathrm{w} / \mathrm{w}) \text { methanol extract } \\
\text { in ointment; } \\
\text { control: ointment base; } \\
\text { positive control: Neomycin } 5 \%(\mathrm{w} / \mathrm{w}) \text {; } \\
\text { treatment: once a day for } 9 \text { days }\end{array}$ & $\begin{array}{l}\text { the highest hydroxyproline content } \\
\text { are comparable with standard } \\
\text { Neomycin }\end{array}$ & - & - & [31] \\
\hline
\end{tabular}

processing of cytokines and growth factors, which finally leads to regeneration of the injured skin and scar formation [89].The herbal products with anti-inflammatory properties may prove beneficial for successful wound healing ( $\triangleright$ Tables 1 to 3 ).

In wounds treated with herbal products, a reduction in leucocytes accumulation and proinflammatory mediators, such as IL and TNF $\alpha$, was promoted. A significant reduction in TNF- $\alpha$, CXCL1 , and CCL-2 levels as well as in neutrophil and macrophage accumulation was observed following topical treatment of $10 \%$ Schinus terebinthifolius oil ointment [71]. Moreover, A. dahurica and $R$. officinale extracts alone and in a combination 1:1 led to a reduction in plasma TNF- $\alpha$, TGF- $\beta 1$, and IL-6 levels [39]. Further, $1 \%, 3 \%$, and $5 \%$ Euterpe oleracea (acai berry) water extract decreased IL-1 $\beta$ expression levels, whereas TNF- $\alpha$ expression levels were similar among different treatment groups in comparison to the vehicle control-treated group [50]. Some research suggests that the M1 to M2 macrophage phenotype transition is a pivotal step in the successful healing process [86]. Reportedly, rosehip oil promoted wound healing by facilitating this transition [66]. Moreover, rosehip oil increased collagen III content in wound tissue and inhibited epithelial-mesenchymal transition during wound healing to improve scars.

It is well known that TGF- $\beta$ produced by macrophages promotes the generation of myofibroblasts from some fibroblasts and increases collagen synthesis, resulting in ECM contraction and subsequent wound closure [90]. Moreover, TGF- $\beta 1$ and TGF$\beta 2$ promote scar tissue, whereas TGF- $\beta 3$ may reduce scar formation [91]. An Achillea asiatica extract (3\%) stimulated collagen expression in Hs68 fibroblasts by activating TGF- $\beta$ and stimulated keratinocyte differentiation and motility by inducing $\beta$-catenin, 
- Table 4 Herbs used for treatment of wounds, human-based studies.

\begin{tabular}{|c|c|c|c|c|}
\hline Herbs & Model of the study & Pharmacological data & Effect & Ref \\
\hline $\begin{array}{l}\text { Achillea } \\
\text { millefolium, } \\
\text { Hypericum per- } \\
\text { foratum extract }\end{array}$ & $\begin{array}{l}\text { double-blind clinical trial; } 140 \text { primi- } \\
\text { parous women: } \\
\text { - } 35 \text { women: without intervention } \\
\text { - } 35 \text { women: placebo ointment } \\
\text { - } 35 \text { women: H. perforatum ointment } \\
\text { - } 35 \text { women: A. millefolium ointment }\end{array}$ & $\begin{array}{l}\text { A. millefolium and } H \text {. perforatum } \\
\text { ointments; } \\
\text { control: ointment base; } \\
\text { treatment: twice a day for } 10 \text { days }\end{array}$ & $\begin{array}{l}\text { both extracts ointments reduced } \\
\text { perineal pain level, } \\
\text { redness, edema, and ecchymosis } \\
\text { of episiotomy wound }\end{array}$ & [79] \\
\hline Aloe vera gel & $\begin{array}{l}\text { prospective, randomized double-blind } \\
\text { clinical; } 90 \text { women after cesarean } \\
\text { operation: } \\
\text { - } 45 \text { women: without intervention } \\
\text { - } 45 \text { women: } A \text {. vera gel }\end{array}$ & $\begin{array}{l}\text { A. vera mucilage gel; } \\
\text { treatment: once after cesarean } \\
\text { operation }\end{array}$ & $\begin{array}{l}\text { no statistically significant } \\
\text { differences between control } \\
\text { and treatment group }\end{array}$ & {$[80]$} \\
\hline $\begin{array}{l}\text { Calendula } \\
\text { officinalis extract }\end{array}$ & $\begin{array}{l}\text { randomized controlled clinical trial; } \\
72 \text { primiparous women with surgical } \\
\text { childbirth: } \\
\text { - } 36 \text { patients: calendula ointment } \\
\text { - } 36 \text { patients: routine care }\end{array}$ & $\begin{array}{l}2 \% \text { hydroalcoholic extract } \\
\text { of } C \text {. officinalis in ointment; } \\
\text { routine care group; } \\
\text { treatment: every } 12 \text { hours for } 10 \\
\text { days }\end{array}$ & $\begin{array}{l}\text { increased speed of cesarean wound } \\
\text { healing }\end{array}$ & [81] \\
\hline grape seed extract & $\begin{array}{l}\text { double blind clinical trial; } 40 \text { patients } \\
\text { with excision of the lesions: } \\
\text { - } 20 \text { patients: cream base } \\
\text { - } 20 \text { patients: extract cream }\end{array}$ & $\begin{array}{l}\text { cream with } 2 \% \text { grape seed extract; } \\
\text { control: cream base; } \\
\text { treatment: twice daily for } 21 \text { days }\end{array}$ & $\begin{array}{l}\text { complete repair of wounds on } \\
\text { day } 8 \text { in the treatment group and } \\
\text { on day } 14 \text { in the placebo group }\end{array}$ & {$[82]$} \\
\hline green tea extract & $\begin{array}{l}\text { randomized, double-blind, placebo- } \\
\text { controlled clinical trial; } \\
99 \text { primiparous women }\end{array}$ & $\begin{array}{l}\text { green tea ointment group; } \\
\text { placebo ointment group; } \\
\text { routine care group; } \\
\text { treatment: } 2 \mathrm{~cm} \text { of the green tea/ } \\
\text { placebo ointments, twice daily for } \\
10 \text { days }\end{array}$ & $\begin{array}{l}\text { better and faster healing in the } \\
\text { green tea group in comparison } \\
\text { to the other } 2 \text { groups; } \\
\text { effective in relieving episiotomy } \\
\text { pain }\end{array}$ & [83] \\
\hline
\end{tabular}

Akt, and keratinocyte differentiation markers [12]. An E. oleracea water extract (5\%) increased type I collagen, VEGF, and fibronectin mRNA expression levels and decreased MMP-1 (collagenase) and IL-1 $\beta$ mRNA expression levels simultaneously, confirming the wound healing activity of herbs [50].

However, although studies on the mechanisms of action of herbal products on wound healing primarily focus on several cytokines and growth factors, the signaling pathways that the products utilize to cause the effect is unclear or not described at all in these studies. Similarly, molecules/active constituents from herbs responsible for wound healing activities as well as their mechanisms of action remain unelucidated.

\section{Antioxidant activity of herbal products}

The production of reactive oxygen species (ROS) (e.g., superoxide anion, hydroxyl radicals, singlet oxygen, and hydrogen peroxide) in the wound may affect the wound healing process [92]. Low ROS levels are essential in stimulating effective wound healing, whereas excessive ROS release results in cellular damage and impaired wound repair [93]. Low ROS levels (1) appear important in coordinating the recruitment of lymphoid cells to the wound site, (2) regulate the formation of blood vessels (angiogenesis) at the wound site and the optimal perfusion of blood into the wound healing area, and (3) protect the wound against bacterial and other microbial infections (antimicrobial activity) [88]. On the contrary, excessive ROS levels can damage cells by oxidation of cellular macromolecules such as lipids, proteins, collagen, proteogly- can, and hyaluronic acid [92]. Antioxidative enzymes [catalase (CAT), peroxidases, peroxiredoxins, and low molecular weight antioxidants] rapidly detoxify ROS and simultaneously affect the wound healing process [94]. Furthermore, some herbal products and their active constituents demonstrate significant antioxidant activity that may facilitate wound healing ( $\sim$ Tables 1 to 3 ). Superoxide dismutase (SOD), CAT, and glutathione (GSH) concentrations in granulation tissue were significantly increased following the topical application of ointment containing 2\% and 5\% (w/ w) ethanolic extract of Alpinia galanga [17]. Moreover, topical application of ointment containing $5 \%$ ethanolic and $5 \%$ aqueous Salix acmophylla extract increased CAT concentration and decreased lipid peroxidation product (malondialdehyde) concentration in granulation tissue [67]. Increased SOD and CAT concentration and reduced lipid peroxidation product concentration were found in granulation tissue of wounded rats treated with herbal preparations with leaf, fruit, and latex of Croton bonplandianum and $\alpha$-tocopherol [46]. The wounded rats treated with latex of $C$. bonplandianum demonstrated increased antioxidant activity, significant wound contraction rate, and higher collagen content compared with other herbal preparations.

\section{Safety of Herbal Therapy}

Following the topical application of herbs used in wound healing, such as Archidium ohioense oil [19], Macroptilium atropurpureum extract [27], Centella asiatica extract [44], mixture of P. zeylanica, 
D. stramonium and A. mexicana [30], Martynia annua and Tephrosia purpurea extracts [78], Bauhinia tomentosa oil [42], Agave americana extract [15], Achyranthes aspera extract [13], Enicostema littorale extract [48], C. longa, Eclipta alba, and Tridax procumbens extracts [23], A. paniculata extract [18], Hydrolea zeylanica extract [25], Pterolobium hexapetalum extract [31], Sesamum indicum extract [34], S. persica extract [33], and Aegle marmelos and Mucuna pruriens extract [14], no irritation, inflammation, toxicity, erythema, eschar, and edema occurred in acute dermal toxicity test and/or skin irritation test in animal wound models ( $\vee$ Tables 1 to 3). Moreover, Calendula officinalis extract [81], green tea extract [83], A. vera gel [80], and Achillea millefolium and Hypericum perforatum extracts [79] showed no redness and edema in humans tested using the REEDA scale ( $\bullet$ Table 4 ). Moreover, none of these above mentioned herbal products demonstrated toxicity or irritation. Unfortunately, the irritation and/or toxicity of the most herbs described in $\mathbf{r}$ Tables $\mathbf{1}$ to $\mathbf{4}$ have not yet been investigated. There is a strong belief among consumers that herbal agents obtained from "natural" plants are "naturally safe" and have no adverse effects. However, the literature has shown that some herbal remedies may cause allergic reactions, erythema, and edema, and several can be responsible for photosensitization [95].

\section{Conclusion}

Herbal products have been used in skin wound care for a prolonged period. Numerous preclinical in vivo studies on animals and few clinical trials have been conducted confirming the activity of herbal products in the stimulation of wound healing. Data from the articles cited in the present review referred to a total of 79 plants and showed that most of these plants exerted a beneficial effect on skin wound healing. Among these herbal products, A. vera gel $[16,38,55,80], C$. longa fresh paste/ethanolic extract $[22,23,55]$, and Nigella sativa seed oil and powder [59-61] were the most examined. A. vera gel showed significant wound healing activity in comparison to tetracycline ointment [38], soframycin ointment [55], and povidone-iodine [16] via its antibacterial mechanism of action [55]. Unfortunately, the results of clinical trials showed no significant differences between the control (women without intervention) and treatment (women after cesarean operation) groups after the topical application of $A$. vera gel [80]. Fresh $C$. longa paste [22], polyherbal formulation containing $C$. longa extract [23], and lotion containing its ethanolic extract [55] increased wound breaking strength, significantly reduced epithelialization, and completed the wound healing process in 15 days. $N$. sativa oil [59], powder [60], and cream with extract [61] increased epithelialization and granulation as well as demonstrated significant wound contraction rate via its antioxidant activity. It is worth mentioning that most analyzed studies showed the potential of the examined plants in wound healing treatment. Only 1 study on Punica granatum pulp showed no promising effects of this plant on wound healing [32]. Notably, none of the herbal products tested as a component of topical preparations for wound healing in the studies cited in this review posed a risk for animals or patients. Indeed, in contrast to synthetic drugs, for which chemical compositions, purity, efficacy, minimal active concentration, and toxicity are well specified, several herbal formulations require further investigation. Nevertheless, it cannot be precluded that herbs may be considered as an important support during conventional therapy or even as synthetic medicament replacements.

Conflict of Interest

The authors declare that they have no conflict of interest.

References

[1] Gonzalez ACDO, Costa TF, Andrade ZDA, Medrado ARAP. Wound healing - a literature review. An Bras Dermatol 2016; 91: 614-620

[2] Rittié L. Cellular mechanisms of skin repair in humans and other mammals. J Cell Commun Signal 2016; 10: 103-120

[3] Barrientos S, Stojadinovic O, Golinko MS, Brem H, Tomic-Canic M. Growth factors and cytokines in wound healing. Wound Rep Regen 2008; 16: 585-601

[4] Caley MP, Martins VL, O'Toole EA. Metalloproteinases and wound healing. Adv Wound Care 2015; 4: 225-234

[5] Briquez PS, Hubbell JA, Martino MM. Extracellular matrix-inspired growth factor delivery systems for skin wound healing. Adv Wound Care 2015; 4: 479-489

[6] Pereira RF, Bartolo PJ. Traditional therapies for skin wound healing. Adv Wound Care 2016; 5: 208-229

[7] Calixto JB. Efficacy, safety, quality control, marketing and regulatory guidelines for herbal medicines (phyto therapeutic agents). Braz J Med Biol Res 2000; 33: 179-189

[8] Maver T, Maver U, Stana Kleinschek K, Smrke DM, Kreft S. A review of herbal medicines in wound healing. Int J Dermatol 2015; 54: 740-751

[9] Budovsky A, Yarmolinsky L, Ben-Shabat S. Effect of medicinal plants on wound healing. Wound Rep Reg 2015; 23: 171-183

[10] Kumar V, Khan AA, Nagarajan K. Animal models for the evaluation of wound healing activity. Int Bul Drug Res 2013; 3: 93-107

[11] Laut M, Ndaong NA, Utami T. Cutaneous wound healing activity of herbal ointment containing the leaf extract of Acalypha indica L. on mice (Mus musculus). J Phys Conf Ser 2019; 1146: 012025

[12] Dorjsembe B, Lee HJ, Kim M, Dulamjav B, Jigjid T, Nho CW. Achillea asiatica extract and its active compounds induce cutaneous wound healing. J Ethnopharmacol 2017; 206: 306-314

[13] Mondal S, Ghosh D, Ganapaty S, Reddy MS, Ramakrishna K. Evaluation of healing potential of Achyranthes aspera L.(Amaranthaceae) seeds in excision, incision, dead space and burn wound model - an in vivo study. Pharmacogn J 2016; 8: 300-306

[14] Toppo FA, Pawar RS. Appraisal on the wound healing activity of different extracts obtained from Aegle marmelos and Mucuna pruriens by in vivo experimental models. Niger J Clin Pract 2016; 19: 753-760

[15] Misra AK, Varma SK. Effect of an extract of Agave americana on wound healing model in experimental animals. J Basic Clin Pharma 2017; 8: 45-48

[16] Khan A, Ashfaq K, ud Din J, Ali A, Tariq A, Ghani S, Ullah N,Sulaman Y, Farooq Ahmad M. Comparative efficacy of Acacia honey and Aloe vera gel on healing of induced lacerated wound in rabbits. Am Sci Res J Eng Tech Sci 2017; 33: 182-187

[17] Shukla R, Rai G, Jain AP. Preclinical evaluation of rhizomes for wound healing activity with Alpinia galanga reducing oxidative status. Asian J Pharm Pharmacol 2015; 1: 65-69

[18] Natarajan S, Pattiyappan S, Rajamani R. Evaluation of C. albicans induced wound healing activity of methanolic leaf extract of Andrographis paniculata. J Sci Tech Invest 2017; 1: 39-49 
[19] Akinpelu BA, Odukoya SOA, Akanni AA, Adelodun ST, Oyedapo OO. Evaluation of wound healing activity of Achidium ohioense (Schimp. ex Mull) oil on albino rats. J Med Plant Herbal Ther Res 2018; 6: 9-30

[20] Toporcer T, Grendel T, Vidinský B, Gal P, Sabo J, Hudák R. Mechanical properties of skin wounds after Atropa belladonna application in rats. J Met Mater Min 2017; 16: 25-29

[21] Moron M], Acero LH. Mayana (Coleus blumei) leaves ointment in wound healing of albino rats (Rattus albus). Int J Food Eng 2017; 3: 18-22

[22] Al Mamun MA, Juyena NS, Khan MAHNA, Islam MA. Comparative effect of turmeric (Curcuma longa) and durba (Cynodon dactylon) on the healing of surgical wounds in cattle (Bos indicus). Asian J Med Biol Res 2018; 4: 164-171

[23] Nasir MA, Mahammed NL, Roshan S, Ahmed MW. Wound healing activity of poly herbal formulation in albino rats using excision wound model, incision wound model, dead space wound model and burn wound model. Int J Res Dev Pharm L Sci 2016; 5: 2080-2087

[24] Elzayat EM, Auda SH, Alanazi FK, Al-Agamy MH. Evaluation of wound healing activity of henna, pomegranate and myrrh herbal ointment blend. Saudi Pharm J 2018; 26: 733-738

[25] Qureshi MS. Chemical composition and wound healing activity of methanolic leaf extract of Hydrolea zeylanica Vahl. by in vivo excision and incision models. Int J Green Pharma 2017; 11: 114-120

[26] Balqis U, Darmawi CDI, Salim MN. Angiogenesis activity of Jatropha curcas L. latex in cream formulation on wound healing in mice. Vet World 2018; 11: 939-943

[27] Ali MS, Rafiq M, Khasim SM. Formulation and evaluation of wound healing activity of Macroptilium atropurpureum in albino wistar rats. World J Pharmac Res 2018; 7: 582-599

[28] Shukla R, Kashaw V. Evaluation of wound healing prospective of Momordica charantia, Pongamia glabra and Piper nigrumon anemic albino rats using incision wound model. Asian J Pharm Pharmacol 2019; 5: 401408

[29] Unamba-Oparah C, Unamba-Oparah IC, Eze CA, Anaga AO. Effects of the methanol leaf extract of Palisota hirsuta in post-surgical wound management. Sokoto J Vet Sci 2018; 16: 91-97

[30] Dev SK, Choudhury PK, Srivastava R, Sharma M. Antimicrobial, antiinflammatory and wound healing activity of polyherbal formulation. Biomed Pharmacother 2019; 111: 555-567

[31] Sathyanarayanan S, Muniyandi K, George E, Sivaraj D, Sasidharan SP, Thangaraj P. Chemical profiling of Pterolobium hexapetalum leaves by HPLC analysis and its productive wound healing activities in rats. Biomed Pharmacother 2017; 95: 287-297

[32] Asadi MS, Mirghazanfari SM, Dadpay M, Nassireslami E. Evaluation of wound healing activities of pomegranate (Punica granatum-Lythraceae) peel and pulp. J Res Med Dental Sci 2018; 6: 230-236

[33] Tatke P, Nehete M, Gabhe S. Evaluation of antioxidant, antimicrobial and wound healing potential of Salvadora persica twig extracts. World J Pharm Res 2017; 6: 1186-1199

[34] Somwanshi SB, Hiremath SN. In vivo evaluation of the wound healing activity of the Sesamum Indicum L. seed extract in novel ethosomal vesicular system. J Drug Deliv Therap 2018; 8: 411-420

[35] Francis P, Masimba PJ, Mwakigonja AR. Evaluation of the wound healing activity of formulated ointments and water preparation from Sida rhombifolia leaf extract. Tanzania J Health Res 2018; 20: 1-8

[36] Solanki R, Mathur V, Purohit SK, Mathur M. Evaluation of wound healing activity of ethanolic extract of Ocimum basilicum and Aegle marmelos leaves in male albino rats. Int J Drug Res Tech 2017; 2: 198-202

[37] Rezaei M, Dadgar Z, Noori-Zadeh A, Mesbah-Namin SA, Pakzad I, Davodian E. Evaluation of the antibacterial activity of the Althaea officinalis L. leaf extract and its wound healing potency in the rat model of excision wound creation. Avicenna J Phytomed 2015; 5: 105-112

[38] Jahandideh M, Hajimehdipoor H, Mortazavi SA, Dehpour A, Hassanzadeh G. Evaluation of the wound healing activity of a traditional compound herbal product using rat excision wound model. Iran J Pharm Res 2017; 16 (Suppl.): 153-163

[39] Yang WT, Ke CY, Wu WT, Harn H], Tseng YH, Lee RP. Effects of Angelica dahurica and Rheum officinale extracts on excisional wound healing in rats. Evid Based Compl Alt Med 2017; 2017: 1583031

[40] Miladiyah I, Prabowo BR. Ethanolic extract of Anredera cordifolia (Ten.) Steenis leaves improved wound healing in guinea pigs. Universa Med 2015; 31: 4-11

[41] Mohsenikia M, Khakpour S, Azizian Z, Ashkani-Esfahani S, Razavipour ST, Toghiani P. Wound healing effect of Arnebia euchroma gel on excisional wounds in rats. Adv Biomed Res 2017; 6: 2

[42] Manjula RR, Uppuluri S, Anand TJ, Adilakshmi V, Gandrapu P, Munagala A. Wound healing effect of methanolic flower extract of Bauhinia tomentosa Linn. with emu oil in rats. J Pharmacogn Phytochem 2017; 6: 247253

[43] Juneja K, Mishra R, Chauhan S, Gupta S, Roy P, Sircar D. Metabolite profiling and wound-healing activity of Boerhavia diffusa leaf extracts using in vitro and in vivo models. J Traditional Compl Med 2019; 10: 52-59

[44] Azis HA, Taher M, Ahmed AS, Sulaiman WMAW, Susanti D, Chowdhury SR, Zakaria ZA. In vitro and in vivo wound healing studies of methanolic fraction of Centella asiatica extract. S Afr J Bot 2017; 108: 163-174

[45] Vijayaraghavan K, Rajkumar J, Seyed MA. Efficacy of Chromolaena odorata leaf extracts for the healing of rat excision wounds. Vet Med 2017; 62: 565-578

[46] Vennila V, Udayakumar R. Wound healing efficacy of herbal preparations of Croton bonplandianum Baill. on excision wound in experimental rats. Curr Trad Med 2017; 3: 38-50

[47] Shekhar P, Joshi A, Malviya S, Kharia A. Wound healing activity of the hydro-alcoholic extract of Datura stramonium leaves in Wistar albino rats. J Drug Deliv Therap 2017; 7: 214-215

[48] Muhamad Ibrahim A, Nagarajan A, Majeed M. Swertiamarin ointment: A traditional approach in cutaneous wound healing. Asian J Pharm Pharmacol 2019; 5: 298-309

[49] Gorda CT, Flores AAU jr. Study on wound healing effect of Milk Bush (Euphorbia tirucalli Linn) in albino mice. Adv Pharm J 2018; 3: 157-161

[50] Kang MH, Choi S, Kim BH. Skin wound healing effects and action mechanism of acai berry water extracts. Toxicol Res 2017; 33: 149-156

[51] Goorani S, Zangeneh MM, Koohi MK, Seydi N, Zangeneh A, Souri N, Hosseini MS. Assessment of antioxidant and cutaneous wound healing effects of Falcaria vulgaris aqueous extract in Wistar male rats. Comp Clin Pathol 2019; 28: 435-445

[52] Hanafi N, Talebpour Amiri F, Shahani S, Enayatifard R, Ghasemi M, Karimpour AA. Licorice cream promotes full-thickness wound healing in Guinea pigs. Marmara Pharm J 2018; 22: 411-421

[53] Kotian S, Bhat K, Pai S, Nayak ], Souza A, Gourisheti K, Padma D. The role of natural medicines on wound healing: a biomechanical, histological, biochemical and molecular study. Ethiop J Health Sci 2018; 28: 759-770

[54] Kim J, Lee CM. Wound healing potential of a polyvinyl alcohol-blended pectin hydrogel containing Hippophae rahmnoides L. extract in a rat model. Int J Biol Macromol 2017; 99: 586-593

[55] Dons T, Soosairaj S. Evaluation of wound healing effect of herbal lotion in albino rats and its antibacterial activities. Clin Phyto Sci 2018; 4: 6

[56] Taweepraditpol S, Chuangsuwanich A, Pradniwat K. Wound healing activity of Lawsonia inermis Linn in rat model. J Med Assoc Thai 2017; 100 (Suppl. 3): 140-144

[57] Rafiee S, Nekouyian N, Hosseini S, Sarabandi F, Chavoshi-Nejad M, Mohsenikia M, Yadollah-Damavandi S, Seifaee S, Jangholi E, Eghtedari D, Najafi H, Ashkani-Esfahani S. Effect of topical Linum usitatissimum on full thickness excisional skin wounds. Trauma Mon 2017; 22: e64930

[58] Shukla R, Kashaw V. Assessment of wound healing potential of Momordica charantia, Pongamia glabra and their combination with Piper nigrum 
on anemic albino rats using excision wound model. Asian J Pharm Pharmacol 2019; 5: 188-198

[59] Javadi SMR, Hashemi M, Mohammadi Y, MamMohammadi A, Sharifi A, Makarchian HR. Synergistic effect of honey and Nigella sativa on wound healing in rats. Acta Cir Bras 2018; 33: 518-523

[60] Paheerathan V, Piratheepkumar R, Kumaran K. Evaluation of wound healing activity of Nigella sativa seed powder on Wistar albino rats. Scholarly J Biol Sci 2017; 6: 60-63

[61] Han MC, Durmus AS, Sağlıyan A, Günay C, Özkaraca M, Kandemir FM, Comakli S, Firat Oztopalan D. Effects of Nigella sativa and Hypericum perforatum on wound healing. Turk J Vet Anim Sci 2017; 41: 99-105

[62] Kurt B, Bilge N, Sözmen M, Aydın U, Önyay T, Özaydın i. Effects of Plantago lanceolata L. extract on full-thickness excisional wound healing in a mouse model. Biotech Histochem 2018; 93: 249-257

[63] Kolhe SS. Evaluation of polyherbal ointment for wound healing activity in Wistar rats. J Drug Deliv Therap 2018; 8: 26-31

[64] Alshammari ND, Fatima N, Nayeem N. Punica granatum rind, a traditional herbal medicine: effect on wound healing. Int J Pharm Res Allied Sci 2017; 6: 53-58

[65] Handoo N, Parrah JD, Athar H, Abrar Gayas M, Imtiyaz T, Bisma S. Wound healing and anti-bacterial efficacy of Rheum emodi and its different extracts on excisional wounds in rabbits. I Entomol Zoology Stud 2018; 6: 1204-1213

[66] Lei Z, Cao Z, Yang Z, Ao M, Jin W, Yu L. Rosehip oil promotes excisional wound healing by accelerating the phenotypic transition of macrophages. Planta Med 2018; 85: 563-569

[67] Sakeena Q, Ansari MM, Sakeena S, Muzamil S, Makhdoomi DM. In vivo assessment of lipid peroxidation and antioxidant profile in aqueous and ethanolic extract ointment of Salix acmophylla leaves in rabbits for wound healing improvement on excisional full thickness skin wounds. Pharma Innovat J 2018; 7: 492-500

[68] Fatima N, Iqbal W, Yaqeen SS. Evaluation of wound healing effects between Salvadora persica ointment and Solcoseryl jelly in animal model. Pak J Pharm Sci 2015; 28: 1777-1780

[69] Ghabaee DNZ, Ebrahimzadeh MA, Akbari J, Amiri FT. Wound healing activity of Sambucus ebulus. Int J Pharm Sci Res 2017; 8: 132-135

[70] Beyranvand F, Gharzi A, Abbaszadeh A, Khorramabadi RM, Gholami M, Gharravi AM. Encapsulation of Satureja khuzistanica extract in alginate hydrogel accelerate wound healing in adult male rats. Inflam Reg 2019; 39: 2

[71] Estevão LRM, Simões RS, Cassini-Vieira P, Canesso MCC, Barcelos LDS, Rachid MA, Câmara CAGD, Evêncio-Neto J. Schinus terebinthifolius Raddi (Aroeira) leaves oil attenuates inflammatory responses in cutaneous wound healing in mice. Acta Cir Bras 2017; 32: 726-735

[72] Ghashghaii A, Hashemnia M, Nikousefat Z, Zangeneh MM, Zangeneh A. Wound healing potential of methanolic extract of Scrophularia striata in rats. Pharm Sci 2017; 23: 256-263

[73] Goorani S, Zangeneh MM, Zangeneh A, Poorshamohammad C, Abiari M, Moradi R, Najafi F, Tahvilian R. Study of wound healing potential of Stevia rebaudiana ethanol extract in male rats. Res J Pharmacogn 2018; 5: 23 30

[74] Talekar YP, Apte KG, Paygude SV, Tondare PR, Parab PB. Studies on wound healing potential of polyherbal formulation using in vitro and in vivo assays. J Ayurveda Integ Med 2017; 8: 73-81

[75] Babaei E, Asghari MH, Mehdikhani F, Moloudizargari M, Ghobadi E, Pouya SRH. The healing effects of herbal preparations from Sambucus ebulus and Urtica dioica in full-thickness wound models. Asian Pac J Trop Biomed 2017; 7: 421-427
[76] Hamid A, Lian CP, Hudin NHS, Ghazali AR, Jufri NF. Zingiber zerumbet rhizomes extract exhibits faster open wound healing in rats. Pharmacog Res 2018; 10: 354-360

[77] Verma RK, Pandey M, Indoria MD, Singh R, Suthar S. Phytochemical investigation and pharmacological evaluation of leaves of Ziziphus mauritiana for wound healing activity in albino rats. Trop J Pharm Life Sci 2018; 5: 8-18

[78] Lodhi S, Jain A, Jain AP, Pawar RS, Singhai AK. Effects of flavonoids from Martynia annua and Tephrosia purpurea on cutaneous wound healing. Avicenna J Phytomed 2016; 6: 578-591

[79] Hajhashemi M, Ghanbari Z, Movahedi M, Rafieian M, Keivani A, Haghollahi F. The effect of Achillea millefolium and Hypericum perforatum ointments on episiotomy wound healing in primiparous women. J Matern Fetal Neonatal Med 2018; 31: 63-69

[80] Molazem Z, Mohseni F, Younesi M, Keshavarzi S. Aloe vera gel and cesarean wound healing; a randomized controlled clinical trial. Glob J Health Sci 2015; 7: 203-209

[81] Jahdi F, Khabbaz AH, Kashian M, Taghizadeh M, Haghani H. The impact of calendula ointment on cesarean wound healing: a randomized controlled clinical trial. J Family Med Prim Care 2018; 7: 893-897

[82] Hemmati AA. The topical effect of grape seed extract $2 \%$ cream on surgery wound healing. Glob J Health Sci 2015; 7: 52-58

[83] Shahrahmani H, Kariman N, Jannesari S, Rafieian-Kopaei M, Mirzaei M Ghalandari, Shahrahmani N, Mardani G. The effect of green tea ointment on episiotomy pain and wound healing in primiparous women: a randomized, double-blind, placebo-controlled clinical trial. Phytother Res 2018; 32: 522-530

[84] Negut I, Grumezescu V, Grumezescu A. Treatment strategies for infected wounds. Molecules 2018; 23: 2392

[85] Rodero MP, Khosrotehrani K. Skin wound healing modulation by macrophages. Int J Clin Exp Pathol 2010; 3: 643-653

[86] Hesketh M, Sahin KB, West ZE, Murray RZ. Macrophage phenotypes regulate scar formation and chronic wound healing. Int J Mol Sci 2017; 18: 1545

[87] Koh TJ, DiPietro LA. Inflammation and wound healing: the role of the macrophage. Expert Rev Mol Med 2011; 13: e23

[88] Landén NX, Li D, Ståhle M. Transition from inflammation to proliferation: a critical step during wound healing. Cell Mol Life Sci 2016; 73: 38613885

[89] Knapinska A, Fields GB. Chemical biology for understanding matrix metalloproteinase function. Chembiochem 2012; 13: 2002-2020

[90] Beanes SR, Dang C, Soo C, Ting K. Skin repair and scar formation: the central role of TGF- $\beta$. Exp Rev Mol Med 2003; 5: 1-22

[91] Shah M, Foreman DM, Ferguson MW. Neutralization of TGF-beta 1 and TGF-beta 2 or exogenous addition of TGF-beta 3 to cutaneous rat wounds reduces scarring. J Cell Sci 1995; 108: 985-1002

[92] Schafer M, Werner S. Oxidative stress in normal and impaired wound repair. Pharmacol Res 2008; 58: 165-171

[93] Dunnill C, Patton T, Brennan J, Barrett J, Dryden M, Cooke J, Leaper D, Georgopoulos NT. Reactive oxygen species (ROS) and wound healing: the functional role of ROS and emerging ROS-modulating technologies for augmentation of the healing process. Int Wound J 2017; 14: 89-96

[94] Kurahashi T, Fujii ]. Roles of antioxidative enzymes in wound healing. J Develop Biol 2015; 3: 57-70

[95] De Smet PA. Health risks of herbal remedies: an update. Clin Pharmaco Ther 2004; 76: 1-17 